\title{
Local adaptation optimizes photoprotection strategies in a Neotropical legume tree under drought stress
}

DOI:

10.1093/treephys/tpab034

\section{Document Version}

Accepted author manuscript

Link to publication record in Manchester Research Explorer

\section{Citation for published version (APA):}

Cordero Herrera, I., Dolores Jimenez, M., Delgado, J. A., Balaguer, L., Pueyo, J. J., \& Rincon, A. (2021). Local adaptation optimizes photoprotection strategies in a Neotropical legume tree under drought stress. Tree Physiology, 41(9), 1641-1657. https://doi.org/10.1093/treephys/tpab034

\section{Published in:}

Tree Physiology

\section{Citing this paper}

Please note that where the full-text provided on Manchester Research Explorer is the Author Accepted Manuscript or Proof version this may differ from the final Published version. If citing, it is advised that you check and use the publisher's definitive version.

\section{General rights}

Copyright and moral rights for the publications made accessible in the Research Explorer are retained by the authors and/or other copyright owners and it is a condition of accessing publications that users recognise and abide by the legal requirements associated with these rights.

\section{Takedown policy}

If you believe that this document breaches copyright please refer to the University of Manchester's Takedown Procedures [http://man.ac.uk/04Y6Bo] or contact uml.scholarlycommunications@manchester.ac.uk providing relevant details, so we can investigate your claim.

\section{OPEN ACCESS}


1 Local adaptation optimizes photoprotection strategies in a Neotropical legume tree

2 under drought stress

3

4 Irene Cordero ${ }^{1,2,3,}{ }^{*}$, María Dolores Jiménez ${ }^{4}$, Juan Antonio Delgado ${ }^{4}$, Luis Balaguer ${ }^{2, \dagger}$,

5 José J. Pueyo ${ }^{1}$, Ana Rincón ${ }^{1}$

6

$7{ }^{1}$ Department of Soil, Plant, and Environmental Quality, Institute of Agricultural

8 Sciences, Spanish National Research Council (ICA-CSIC), Serrano 115-bis, 28006

9 Madrid, Spain.

$10{ }^{2}$ Department of Plant Biology I, Universidad Complutense de Madrid, José Antonio 11 Nováis 10, 28040, Madrid, Spain.

$12{ }^{3}$ Department of Earth and Environmental Sciences, The University of Manchester,

13 Michael Smith Building, Oxford Road, Manchester, M13 9PT, UK

$14{ }^{4}$ Department of Biodiversity, Ecology and Evolution, Universidad Complutense de 15 Madrid, José Antonio Nováis 10, 28040, Madrid, Spain

16 'Deceased

17

18 *Author for correspondence: Irene Cordero

19 Tel.: +44 16130 68074; e-mail: irene.cordero@manchester.ac.uk

\section{Keywords}

22 Caesalpinia spinosa (tara), common garden, desiccation, leaflet closure, light stress, local 23 adaptation, phenotypic diversity, photosynthetic response.

25 Running head: Local adaption and photoprotection under drought 


\section{Abstract}

27 Photoprotection is a plant functional mechanisms to prevent photooxidative damage by

28 excess light. This is most important when carbon assimilation is limited by drought, and as such, it entails a trade-off between carbon assimilation $v s$ stress avoidance. The ecological adaptation of plants to local water availability can lead to different photoprotective strategies. To test this, we used different provenances of Caesalpinia spinosa (Mol.) Kuntze (commonly known as "tara") along a precipitation gradient. Tara is a Neotropical legume tree with high ecological and commercial value, found in dry tropical forests, which are increasingly threatened by climate change. Morphological and physiological responses of tara provenances were analysed under three different treatments of drought and leaflet immobilization i.e., light stress, in a common garden greenhouse experiment.

Tara quickly responded to drought by reducing stomatal conductance, evapotranspiration, photochemical efficiency, carbon assimilation and growth, while increasing structural and chemical photoprotection (leaflet angle and pigments for thermal dissipation). Leaflet closure was an efficient photoprotection strategy with overall physiological benefits for seedlings as it diminished the evaporative demand and avoided photodamage, but also entailed costs by reducing net carbon assimilation opportunities. These responses depended on seed origin, with seedlings from the most xeric locations showing the highest dehydration tolerance, suggesting local adaptation and highlighting the value of different strategies under distinct environments. This plasticity on its response to environmental stress allows tara to thrive in locations with contrasting water availability.

Our findings increase the understanding of the factors controlling the functional ecology of tara in response to drought, which can be leveraged to improve forecasts of changes in its distribution range, and for planning restoration projects with this keystone tree species. 


\section{Introduction}

53 Global change scenarios predict higher variability and intensification of El Niño cycles

54 and fluctuating patterns of fog formation in the Pacific coast of South America, with

55 unforeseeable consequences for dry ecosystems (IPCC 2014, Tognetti 2015). Trees can display different adaptive strategies to deal with adverse environmental conditions, for which the phenotypic and genotypic variability are important features (Wennersten and Forsman 2012). The tree phenotype is defined by the balanced combination of speed on resource acquisition $v s$ tissue longevity, resource overspend $v s$ conservation, hydraulic

60 efficiency $v s$ cavitation resistance, growth $v s$ defence, whose plasticity and/or local

61 adaptation allows trees to thrive in a range of environments (Díaz et al. 2016). Stomatal

62 closure is an effective mechanism of plants to avoid water loss, but it also limits $\mathrm{CO}_{2}$

63 diffusion and photosynthesis. In those circumstances, light energy that exceeds the

64 capacity for photosynthesis leads to over-excitation of the photosynthetic apparatus,

65 causing photoinhibition and photodamage (Lawlor and Tezara 2009). This phenomenon

66 is exacerbated in environments close to the equator where the photosynthetically active

67 radiation (PAR) is soaring (Bouvet et al. 2002). Plants display two main mechanisms to

68 escape photoinhibition and photodamage, 1) structural avoidance of the excessive

69 absorption of luminous energy, e.g., reorientation of leaves and chloroplasts, leaflet

70 closure, and 2) chemical adjustments to deal with the excess of absorbed light, e.g.,

71 increase of photosynthetic pigments involved in thermal energy dissipation (Raven 2011).

72 Photosynthetic pigments, such as chlorophylls and carotenoids, are involved in light

73 harvesting and photoprotection. They quickly respond to environmental stressors and,

74 therefore, the study of their composition and of the ratios between them provides a

75 diagnosis of the functionality of the photosynthetic apparatus (Esteban et al. 2015). 
76 Caesalpinia clade is a group of around 200 species that thrives in an extensive range of

77 environments, including seasonally dry tropical forests and woodlands (Gagnon et al. 2019). Species in this clade present abundant adaptations to dry conditions, such as drought deciduousness and rapid post-drought leaf flush (Gagnon et al. 2019). Caesalpinia spinosa (Mol.) Kuntze, commonly known as tara, is a legume tree of high 81 ecological (keystone species) and commercial value (high tannins and gums concentration in seeds) widely distributed along the occidental South American coast (de la Cruz Lapa 2004, Larrea 2011). Tara seedlings have been evidenced to present a dehydration-avoiding strategy through a tight stomatal control of photosynthesis and structural photoprotection by leaflet closure triggered by the decrease in air humidity (Balaguer et al. 2011). As a rare exception within the Caesalpinia clade (Gagnon et al. 2019), tara is often found as dominant tree of dry tropical forests and in coastal forests maintained by seasonal fogs as the sole water resource (e.g., Lomas biome) (Canziani Amico 2002, Ramírez et al. 2012). The Lomas are ecological valuable formations that trap water and truly biodiversity hotspots (Sotomayor and Drezner 2019). In dry ecosystems, water shortage affects many physiological and morphological parameters, hindering plant survival, growth and/or fitness (McDowell et al. 2008, Lawlor and Tezara 2009). However, few studies have evaluated the capacity of Caesalpinia species to withstand drought (Dombroski et al. 2011, Pineda-García et al. 2015, Chirino et al. 2017). Previously, we evaluated the response of tara to the environmental conditions of the 96 Atiquipa fog forest (Lomas ecosystem), an invaluable oasis in the middle of the 97 inhospitable Peruvian coastal desert (Balaguer et al. 2011). Strikingly, despite thriving in a very unique environment controlled by fog pulses, tara plants did not show local

99 acclimation or specialisation to these water pulses. Instead, they displayed a rather 100 opportunistic behaviour, which would connect with the proposed human-favoured origin 
101 of this forest (Balaguer et al. 2011). Additional support for this hypothesis is that the

102 Caesalpinia clade presents strong phylogenetic biome conservatism (Gagnon et al. 2019).

103 However, tara is found in remarkably different environments (e.g., fog forests, tropical

104 dry and humid forests), which offers a unique opportunity to study potential morpho-

105 physiological and phenotypic variations of this tree species in response to environmental

106 conditions associated with climate change (e.g. light excess, drought).

107 Our overall objective was to test the response of contrasting tara provenances to water 108 and light stress, evaluated in a common garden greenhouse experiment. We analysed the 109 consequences of the two potential photoprotective strategies of tara by forcing some

110 leaflets to remain open (i.e., structural photoprotection) and by evaluating the effects of

111 the variation of photosynthetic pigments on the maximum photochemical efficiency of

112 plants (i.e., chemical photoprotection). Due to the low genetic variability of tara along its

113 distribution range and its proposed human-favoured dispersal (Balaguer et al. 2011), we

114 initially hypothesized that seedlings from different provenances grown under similar

115 conditions would show similar responses to drought stress. Alternatively, given the ability

116 of tara to thrive in different environments (Canziani Amico 2002, de la Cruz Lapa 2004),

117 possible variations on tara seedling response attributable to local adaptation to the original

118 ecological conditions could be also expected. If the latter scenario is true, we expected

119 that the endurance of seedlings to simulated drought would depend on the availability of

120 water in their origin locations, based on the prediction that tara photoprotective strategy

121 (i.e., leaflet closure and/or pigment variation) would avoid photodamage under water

122 shortage, but with a different carbon assimilation cost depending on the provenance.

123 Specifically, under this alternative hypothesis of local adaptation, we predicted that tara

124 provenances from areas with higher water availability would be more sensitive to

125 combined induced drought and light stress, and accordingly they (i) would completely 
126 close their leaflets and stomata under water stress to preserve their photosynthetic

127 apparatus but with a high assimilation cost; and/or (ii) would imbalance the ratios of

128 photosynthetic pigments, promoting the investment in energy dissipation pigments to

129 avoid photodamage.

130 Tara-dominated forests are quite abundant in certain areas of its distribution range,

131 particularly in Peru (Larrea 2011). However, in the last century, intensive land use and

132 severe deforestation have threatened many tara-dominated forests and the local human-

133 populations that depend on them (Larrea 2011, Balaguer et al. 2011). Planning successful

134 restoration strategies of these tara-dominated ecosystems is a major goal (Balaguer et al.

135 2011, Cordero et al. 2017), which requires gaining knowledge about the eco-

136 physiological response of these forests and the ability of the dominant tree, tara, to cope

137 with local environmental constraints.

138 


\section{Materials and Methods}

\section{$140 \quad$ Plant material}

141 Caesalpinia spinosa (Fabaceae) is a long-living non-nodulating drought deciduous tree

142 of 2-5 m height, with hypostomatous bipinnate leaves, terminal yellow inflorescences and

143 long pod-flat fruits with 4-7 seeds (Lewis et al. 2005, Cordero, Ruiz-Díez, et al. 2016).

144 Seeds from different individuals were collected along a latitudinal and water availability

145 gradient in Ecuador and Peru (Fig. 1), in four locations: Andurco, Polán, Jerusalem and

146 Atiquipa . Andurco and Atiquipa locations, respectively, receive the highest and lowest

147 annual water inputs, while Polán and Jerusalem get intermediate amounts of annual water

148 but with different precipitation seasonality (i.e., Jerusalem receives a similar low amount

149 of water throughout the year, while Polán has wetter months, showing a higher value of

150 the precipitation of the wettest quarter of the year).

151 Seeds were scarified ( $96 \% \mathrm{H}_{2} \mathrm{SO}_{4}, 45 \mathrm{~min}$ ), soaked in distilled water for $48 \mathrm{~h}$, and sown 152 in $250 \mathrm{ml}$ containers with $3: 1(\mathrm{v}: \mathrm{v})$ peat:vermiculite. Seedlings were grown for two 153 months in a growth chamber $\left(250 \mu \mathrm{mol} \mathrm{m} \mathrm{m}^{-2} \mathrm{~s}^{-1}, 24{ }^{\circ} \mathrm{C}\right.$ and $60 \%$ humidity $)$ and then

154 transferred to a greenhouse with semi-controlled conditions with $23 / 20{ }^{\circ} \mathrm{C}$ day/night 155 temperature, $45 / 50 \%$ relative air humidity, and $1000 \mu \mathrm{mol} \mathrm{m} \mathrm{m}^{-2} \mathrm{~s}^{-1}$ PAR radiation, 156 monitored with four light and temperature sensors placed at plant height, and a sensor for 157 general greenhouse air humidity (HOBO, Onset Computers, Pocasset, MA, USA). After 158 fifteen days of acclimatisation in the greenhouse, 2.5 month old seedlings were 159 transplanted to individual $3.5 \mathrm{~L}$ pots $(11 \times 35 \mathrm{~cm})$ with peat:vermiculite $(3: 1, \mathrm{v}: \mathrm{v})$, 160 supplemented with $2 \mathrm{~g}^{-1}$ fertilizer (Osmocote NPK 11:11:18 $+2 \mathrm{MgO}_{2}+$ 161 microelements), and regularly watered. Plants were grown for approximately one year 162 and rotated weekly to minimize position effects. Mean seedling height and diameter at 
163 the start of the treatments (16 months old seedlings) were of $43.6 \pm 7.3 \mathrm{~cm}$ and $9.0 \pm 0.9$

$164 \mathrm{~mm}$, respectively.

165 Experimental design

166 A factorial design was used to evaluate the main effects and interactions of 1) seed

167 provenance, 2) leaflet immobilization (i.e., light stress), and 3) drought, on the physiology

168 and growth of $C$. spinosa along a drought and rewetting pulse. The factor immobilization

169 (mobile and immobile leaflets) was tested within the same seedling. Each treatment had 170 eight seedlings $(\mathrm{n}=8$; total of 96 plants). The factor provenance consisted of four treatments: 1) Andurco (AND), 2) Polán (POL), 3) Jerusalem (JER) and 4) Atiquipa (ATQ). The factor leaflet immobilization had two treatments: 1) mobile and 2)

173 immobilized leaflets. In each seedling, two complete pinnae ( $\sim 5 \%$ of plant's leaflets)

174 were immobilized in fully expanded mature leaves, with transparent Plexiglas pieces

175 installed perpendicularly to the rachis (Fig. 2), in order to avoid the structural 176 photoprotection by leaflet closure and induce light stress. Physiological measurements

177 were carried out on the mobile and its symmetric immobilized pinna. To check for a 178 possible effect of immobilization on the water status of plants, four seedlings per 179 treatment were kept not immobilized throughout the experiment as control.

180 Drought consisted of three treatments: 1) well-watered control (C), 2) moderate drought 181 (D1), and 3) severe drought (D2). Each pot was daily weighted and the $75 \%$ or the $50 \%$ 182 of the water loss was replaced in D1 and D2 respectively, while control pots received the $183100 \%$ of the water lost. Drought lasted 22 days and afterwards all pots were rehydrated 184 during 40 days to initial water content (see Fig. S1 available as Supplementary Data at 185 Tree Physiology Online), which is similar to the soil moisture found in Atiquipa forest at 186 the end of the wet season (Balaguer et al. 2011). Substrate water content was monitored 187 with a time domain reflectometer (TDR) (HH2 Moisture Meter with WET-2 sensor, 
188 Delta-T Devices Ltd., UK). The 22 days of drought were enough to achieve very low 189 water potentials and to observe clear effects on the seedling physiology, but no so extreme 190 for them to shed the leaves.

191 Water status, morphology and seedling growth

192 Midday water potential ( $\left.\Psi_{\text {mid }}\right)(12: 30-14: 00$ solar time) was measured with a Schölander

193 chamber (SKPM 1400, Skye Instruments Ltd., UK) in a pinna per plant. The last two

194 leaflets of a pinna with $\sim 4 \mathrm{~cm}$ of rachis were selected, as previously described for legumes

195 with composite leaves (Gullo et al., 2003). No interference of immobilization on seedling

196 water potential was found $\left(p_{\text {immobilization }}=0.676\right.$; $\left.p_{\text {immobilization } \times \text { drought }}=0.737\right)$.

197 Seedling height and diameter were measured every two weeks for two months since the 198 beginning of the drought period. Relative growth $(R G)$ was calculated as $R G=\left(X_{f}-X_{o}\right)$

199 / $\mathrm{X}_{\mathrm{o}}$; being $\mathrm{X}_{\mathrm{f}}$ the final height or diameter and $\mathrm{X}_{\mathrm{o}}$ the initial one.

200 Leaflet movement and photosynthetic response

201 To monitor structural photoprotection, leaflet angle was measured with a protractor at midday (11:30-15:00 solar time), from $0^{\circ}$ (completely parallel to the horizon; open leaflets) to $90^{\circ}$ (vertical position, completely closed leaflets).

204 To monitor the physiological status of seedlings, net carbon assimilation (A), stomatal

205 conductance $\left(g_{\mathrm{s}}\right)$ and transpiration $(\mathrm{E})$ of four seedlings per treatment were measured with a portable photosynthesis system (Li-Cor 6400, LiCor Inc., USA), at midmorning (9:00-

207 11:30 solar time). Mature attached leaflets were kept inside the cuvette under a constant 208 radiation of $750 \mu \mathrm{mol} \mathrm{m} \mathrm{m}^{-2} \mathrm{~s}^{-1}$ (previously tested as a non-saturating light that allowed an 209 optimal photosynthetic rate), $\sim 20^{\circ} \mathrm{C}$ temperature, and $\mathrm{CO}_{2}$ flux of $400 \mu \mathrm{mol} \mathrm{s}{ }^{-1}$, for 2

210 min. Three replicated records were logged per pinna and their mean was used for data 211 analyses. Leaflet area inside the cuvette was measured with the software ImageJ v.1.47 212 and used to recalculate the photosynthetic parameters. Water use efficiency (WUE), i.e. 
213 the amount of water used in the production of biomass instantly, was estimated as the

214 assimilation per transpiration rate $(\mathrm{A} / \mathrm{E})$. In order to measure these variables in pinnae

215 with partially closed leaflets, they were forced open to enter the cuvette. This did not

216 damage the leaflets and they recovered their leaflet angle as soon as they were outside the

217 cuvette. However, if the leaflets were completely or almost completely closed, they were

218 inserted as they were, i.e., closed, to avoid damaging them.

219 The photosynthetic capacity of seedlings was evaluated by measuring the fluorescence of 220 chlorophyll $a$ with a Portable Chlorophyll Fluorometer (PAM 2000, Walz, Germany),

221 and maximum quantum yield of photosystem II $\left(\mathrm{F}_{\mathrm{v}} / \mathrm{F}_{\mathrm{m}}\right)$ was determined at predawn in 222 dark adapted leaflets according to Genty et al. (1989). Three replicated measurements 223 were made per pinna, and their mean was used as a replicate for analyses. Completely 224 closed leaflets were carefully open to take fluorescence measurements, which did not 225 change leaflet angle afterwards.

226 To evaluate seedling chemical photoprotection, photosynthetic pigments were measured 227 in four seedlings per treatment previous to the end of the drought period (day 17). One 228 leaflet per plant was collected at midday, immediately frozen in liquid nitrogen and 229 preserved at $-80{ }^{\circ} \mathrm{C}$ until analysis. After extraction with acetone, chlorophylls $(a$ and $b)$ 230 and carotenoids, including $\beta$-carotene ( $\beta$-Car), neoxanthin (Neo), lutein (Lut) and the 231 different pigments of the xanthophyll cycle (violaxanthin (V), antheraxanthin (A) and 232 zeaxanthin (Z)), were separated by high-performance liquid chromatography (HPLC, 233 Waters Corp., Milford, MA, USA) as described in Masuda et al. (2002). Total chlorophyll 234 content $(\mathrm{Chl} a+b)$ was expressed by leaflet area. Content of individual carotenoids ( $\beta$ 235 Car) or the sum of different carotenoids $(\mathrm{V}+\mathrm{A}+\mathrm{Z}$ and total carotenoids) was expressed 236 with respect to the total chlorophyll content $(\mathrm{Chl} a+b)$. The ratios $\mathrm{Chl} a / \mathrm{Chl} b$ and $237 \mathrm{Neo+Lut} / \beta$-Car that indicate the different relative investment on light harvesting 
complexes $v s$ reaction centres, and the ratio $\mathrm{A}+\mathrm{Z} / \mathrm{V}+\mathrm{A}+\mathrm{Z}$ indicative of de-epoxidation of pigments in the xanthophyll cycle were also calculated.

241 The complete dataset was checked for normality, homoscedasticity and outliers.

242 Variables measured repeatedly on the same seedling along time (i.e., $\Psi_{\text {mid }}$, leaflet angle,

$243 \mathrm{~A}, g_{\mathrm{s}}, \mathrm{WUE}, \mathrm{F}_{\mathrm{v}} / \mathrm{F}_{\mathrm{m}}$, height, diameter and $\mathrm{RG}$ ) were analysed by lineal mixed models

244 (LMM) for repeated measures, considering the provenance, leaflet immobilization, 245 drought and time as fixed factors, and the seedling as random factor. Variables measured only once (i.e., pigment contents) were analysed by LMM, considering the same factors except time. Non-significant interactions were eliminated from models, following the hierarchical principle. In all cases, post-hoc comparisons of means among treatments were done by Bonferroni test $(\mathrm{p}<0.05)$. Relative change ratio was calculated as the value of the variable under severe drought divided by the value of the mobile well-watered control. Differences of this ratio between immobilization treatments were evaluated by LMM, considering leaflet immobilization as fixed factor, and the seedling as random factor.

The relationship between structural or chemical photoprotection responses and the physiological status of seedlings facing drought was explored by fitting linear or quadratic regressions between leaflet angle and water potential, transpiration, net assimilation and $F_{v} / F_{m}$, and between $F_{v} / F_{m}$ and ratios of the different photosynthetic pigments. When the regression analyses included all provenances, a test to confirm parallelism among slopes was performed $(\mathrm{p}<0.05)$. Finally, correlation analyses between the response of tara to

260 drought and the climatic variables of the sites of provenance were performed with the non-parametric Spearman correlation test $(\mathrm{p}<0.05)$. All analyses were carried out with the software SPSS v.24 (IBM Corporation Software Group, Somers, NY, US). 


\section{Results}

265 Photoprotection outcomes under drought: effects of seedling provenance

266 Drought and leaflet immobilization triggered multiple responses in tara that were 267 dependent on seedling provenance for some traits (Table S1 available as Supplementary

268 Data at Tree Physiology Online), such as leaflet water potential, carbon assimilation,

269 stomatal conductance, $\mathrm{F}_{\mathrm{v}} / \mathrm{F}_{\mathrm{m}}$, growth rate and pigment contents.

270 Leaflet water potential $\left(\Psi_{\text {mid }}\right)$ significantly declined with drought (i.e., 1.5 and 2.3 times

271 lower values than control in moderate and severe drought, respectively), and this effect 272 was dependent on the provenance ( $\left.\mathrm{p}_{\mathrm{D} \times \mathrm{P}}<0.001\right)$ (Fig. 3a; Table S1). Together with the 273 significant negative relations between $\Psi_{\text {mid }}$ and leaflet angle $\left(\mathrm{R}^{2}=0.551 ; \mathrm{p}<0.001\right)$, and 274 leaflet angle and transpiration $\left(\mathrm{R}^{2}=0.441 ; \mathrm{p}<0.001\right)$, this likely indicated that leaflet 275 closure was activated to reduce evapotranspiration.

276 In parallel, drought activated leaflet closure similarly in all provenances (Fig. 3b), which 277 additionally slowed down or even stopped (severe drought) their relative growth (Fig. S2; 278 Table S1; available as Supplementary Data at Tree Physiology Online). Coincident with $\Psi_{\text {mid }}$ decline, drought and to a lesser extent leaflet immobilization, prompted a quick stomatal closure of seedlings and subsequent drop of net carbon assimilation (reductions of $40 \%$ and $88 \%$ respectively in moderate and severe drought compared with well watered control seedlings, and of $10 \%$ in immobilized compared with mobile leaflets) (Fig. 4a, b; Table S1). Drought negatively affected the WUE of seedlings, i.e., although transpiration decreased, carbon assimilation decreased to a greater extent (Fig. 4c). On average, the provenance from the driest location (ATQ) was the most efficient in the use of water $(\mathrm{p}$ provenance $=0.014)($ Fig. $4 \mathrm{c})$. As drought stress progressed, seedling maximum quantum yield $\left(\mathrm{F}_{\mathrm{v}} / \mathrm{F}_{\mathrm{m}}\right)$ decreased $(9 \%$ in severe drought respect to well watered control, no effect of moderate drought), and a significant drought $\times$ immobilization interaction 
289 (i.e., double drought and light stress) was observed (Fig. 4d; Table S1). In fact, a reduction

290 of $15 \%$ in $\mathrm{F}_{\mathrm{v}} / \mathrm{F}_{\mathrm{m}}$ was observed in immobilized leaflets under severe drought compared to

291 well-watered mobile control leaflets, while the decrease was of $5 \%$ for mobile leaflets,

292 which was indicative of structural photoprotection. The negative effect of severe drought

293 on $F_{v} / F_{m}$ on mobile and immobilized leaflets, and on its recovery after drought, was

294 particularly pronounced in AND (wettest) compared with ATQ (driest) provenance (Fig.

$2954 d)$.

296 After rewetting, $\Psi_{\text {mid }}$ rose, leaflets became nearly horizontal again, and growth restarted,

297 but $\Psi_{\text {mid }}$ of POL and JER provenances took longer time to rise (POL did not fully recover)

298 (Fig. 3), and seedlings that had been under severe drought did not completely recuperate

299 the relative growth in diameter (Fig. S2). In the rehydration phase, previous leaflet closure

300 during drought proved to be an effective mechanism for recovering net carbon

301 assimilation in JER and ATQ (i.e., higher A rates in mobile than immobilized leaflets

302 during rehydration) (Fig. 4a).

303 Drought and leaflet immobilization activated a higher relative investment of seedlings in

304 thermal energy dissipation to protect the photosynthetic apparatus (chemical

305 photoprotection), i.e., Neo+Lut/ $\beta$-Car and $\mathrm{A}+\mathrm{Z} / \mathrm{V}+\mathrm{A}+\mathrm{Z}$ (de-epoxidation state) ratios

306 increased $6 / 17 \%$ and $47 / 69 \%$ more than control in moderate/severe drought,

307 respectively, and $2 \%$ and $22 \%$ more in immobilized than mobile leaflets, respectively)

308 (Fig. 5a, b; Table $\mathrm{S} 1$ ). In the case of $\mathrm{A}+\mathrm{Z} / \mathrm{V}+\mathrm{A}+\mathrm{Z}$ ratio, a drought $\mathrm{x}$ immobilization

309 interaction was also observed $\left(\mathrm{p}_{\mathrm{D} \times \mathrm{I}}<0.001\right)$, i.e., under severe drought this ratio

310 increased $38 \%$ in mobile leaflets, while it did $118 \%$ in immobilized ones, compared to

311 the mobile well-watered controls. The strength of these effects depended on the

312 provenance; Neo+Lut/ $\beta$-Car significantly increased due to drought in AND or to drought

313 and leaflet immobilization in POL (Fig. 5a), and $A+Z / V+A+Z$ increased with severe 
314 drought in both provenances (AND, POL) mainly in immobilized leaflets (double drought

315 and light stress interaction) (Fig. 5b). Total chlorophyll content (Chl $a+b)$ remained

316 constant across treatments (Fig. 5c), but Chla/Chl b ratio was significantly higher in AND

317 (wettest) than in ATQ (driest) provenance (Fig. 5d), and the opposite happened for $\beta$ -

318 Car/Chl content (Fig. S3 available as Supplementary Data at Tree Physiology Online).

319 Total VAZ pool ( $\mathrm{V}+\mathrm{A}+\mathrm{Z} / \mathrm{Chl})$ was also highest in AND provenance (Fig. S3b). No

320 significant effects were detected in the amount of total carotenoids/Chl (Fig. S3c).

321 Relative change ratio evidenced structural and chemical photoprotection together with a

322 decrease in the physiological activity and growth of seedlings with respect to well-

323 watered control ones, summarizing the main effects of severe drought (Fig. 6). Clear

324 significant benefits of leaflet closure on seedlings were evidenced in the case of de-

325 epoxidation state $(\mathrm{A}+\mathrm{Z} / \mathrm{V}+\mathrm{A}+\mathrm{Z})$ and $\mathrm{F}_{\mathrm{v}} / \mathrm{F}_{\mathrm{m}}$ (i.e., less photodamage in mobile leaflets),

326 and marginally for Neo+Lut $/ \beta$-Car ratio. Net carbon assimilation per unit of leaf area

327 exposed to the sun (A) remained the same in mobile and immobilized leaflets (Fig. 6),

328 suggesting that the main cost of leaflet closure is the reduction of the carbon assimilation

329 opportunities, as mobile leaflets highly reduced the leaf area exposed.

330

331

Relationships of seedling traits and climatic variables

332 The balance between physiological activity and photoprotection depended on seedling

333 provenance (Fig. 7). When considering only mobile leaflets at maximum drought stress

334 (day 22), a clear negative relationship between $\Psi_{\text {mid }}$ and leaflet angle was revealed in all

335 provenances, although to a lesser extent in ATQ seedlings (driest area) (Fig. 7a). The

336 higher leaflet closure at maximum drought stress translated into a significant negative

337 relationship of structural photoprotection with transpiration and net carbon assimilation

338 rates for AND and POL (Fig. 7b,c), pointing to higher stomatal closure and assimilation 
costs under drought for the provenances with wetter conditions than for the drier ones. In

340 all cases, as leaflets closed, $\mathrm{F}_{\mathrm{v}} / \mathrm{F}_{\mathrm{m}}$ diminished, particularly in AND seedlings (wettest

341 habitat) (Fig. 7d).

342 Focusing on the relationship between structural and chemical photoprotection, a negative

343 relationship between $\mathrm{F}_{\mathrm{v}} / \mathrm{F}_{\mathrm{m}}$ with $\mathrm{Neo}+\mathrm{Lut} / \beta$-Car was only observed for seedlings from

344 the wettest areas (AND, POL), but not for the driest ones (JER, ATQ) (Fig. 7e). A weak

345 negative regression between $\mathrm{F}_{\mathrm{v}} / \mathrm{F}_{\mathrm{m}}$ and $\mathrm{A}+\mathrm{Z} / \mathrm{V}+\mathrm{A}+\mathrm{Z}$ was observed when all data were

346 jointly analysed $\left(\mathrm{R}^{2}=0.041 ; \mathrm{p}=0.048\right)$, but when analysed by provenance, no clear

347 effects were detected (slight trend in AND) (Fig. 7f).

348 Significant correlations between some drought-responsive tara traits and the climatic

349 conditions of the respective site of seed provenance were found (Fig. 8). A relation

350 between precipitation seasonality and the $\Psi_{\text {mid }}$ (positive) (Fig. 8a) and $g_{\mathrm{s}}$ (negative) (Fig.

$3518 \mathrm{~b}$ ) of seedlings under drought was observed, which was not observed in well-watered

352 seedlings. The number of dry months was also significantly related with the degree of

353 leaflet closure (negative) only in drought seedlings (Fig. 8c), and with the WUE

354 (positive). Finally, there was a significant correlation between the annual water input and

$355 \quad F_{v} / F_{m}$ (negative in seedlings under drought) (Fig. 8e) and the reduction of $R G$ in height

356 between well-watered seedlings and drought ones (positive) (i.e., provenances from

357 wetter areas grew more without water limitation, but under drought, their relative height

358 growth was drastically reduced) (Fig. 8f). Most of these correlations were only apparent

359 under drought conditions (induced variation), except WUE, which showed the same trend

360 under well-watered and drought conditions (constitutive variation). 


\section{Discussion}

363 Our findings show that tara quickly responded to drought by increasing structural and

364 chemical photoprotection (leaflet angle, pigments related to thermal dissipation), while

365 reducing stomatal conductance and evapotranspiration. Combined drought and light

366 stress negatively affected the photochemical efficiency of seedlings, which further

367 increased the chemical photoprotection response. Main benefits of leaflet closure were

368 the reduction of the evaporative demand and photodamage, while the main cost was the

369 reduction of the carbon assimilation opportunities. But, contrary to that initially expected,

370 this response was dependent on the seed origin, supporting our alternative hypothesis of

371 local adaptation.

Mechanisms to avoid photoinhibition and photodamage under drought and light stress

373 As water shortage increased, tara closed the leaflets as a mechanism to diminish the

374 exposed leaf area (Fig. 3), subsequently decreasing the evaporative demand and the

375 excess of photonic energy in photosystems. This movement of leaves to reduce light

376 interception and photodamage has previously been observed and experimentally

377 manipulated in other woody species such as Cistus albidus L. (Oliveira and Peñuelas

378 2002) or the legume tree Robinia pseudoacacia L. (Arena et al. 2008). Tara displayed a

379 similar photoprotection response in a previous field study (Balaguer et al. 2011), where

380 reduced air humidity and light stress triggered leaflet closure. Under the semi-controlled

381 conditions of the current experiment, tara regulated the orientation of its leaflets closure

382 depending on the stress level (completely closed under severe drought but not under

383 moderate drought) and this movement was reversible, returning to its original position

384 upon rewetting. Leaves less exposed have lower temperatures and therefore less

385 transpiration and water loss (Kao and Forseth 1992). Additionally, plants can decrease

386 water loss by stomatal closure, but in exchange, this limits $\mathrm{CO}_{2}$ capture and the 
availability of $\mathrm{C}$ in the carboxylation sites of the chloroplasts, resulting in an excess of energy that may end in photodamage (Lawlor and Tezara 2009, Karabourniotis et al. 2014). In fact, leaf angle is regulated by PSII (Huang et al. 2014), and when $F_{v} / F_{m}$

390 decreases, leaf angle becomes more perpendicular to sunrays to avoid further 391 photoinhibition, as we observed for tara (Fig. 7). In our study, leaflet closure was further 392 evidenced as an effective strategy allowing tara to resist combined stresses (light and 393 drought). A clear decrease in $\mathrm{F}_{\mathrm{v}} / \mathrm{F}_{\mathrm{m}}$ under severe drought was observed (Fig. 4), especially 394 in immobilized leaflets, which slowly recovered afterwards compared with mobile 395 leaflets, suggesting a certain degree of photodamage (Osmond 1994, Llorens et al. 2003).

Tara also activated chemical photoprotection mechanisms to alleviate negative drought and light stress effects (Fig. 5). Variations in Neo+Lut/ $\beta$-Car ratio can be interpreted in

398 terms of differential relative investment in light harvesting complexes (LHC) and reaction centres (RC), as Neo and Lut are carotenoids mainly present in LHC and $\beta$-carotene is basically found in RC (Esteban et al. 2015). This ratio has previously been used to estimate differential relative investment in LHC and RC under other environmental stressors such as nitrogen deposition (Arróniz-Crespo et al. 2008, Ochoa-Hueso et al. 2014). In tara, this ratio increased under severe drought, especially in immobilized

404 leaflets, suggesting a greater relative investment in LHC and thus in thermal energy 405 dissipation, while it was lowest in well-watered seedlings, probably implying a greater 406 relative investment in $\mathrm{RC}$, and therefore photosynthesis prioritization. The constant levels 407 of Chl $a+b$ detected for all the factors analysed in our greenhouse experiment could be 408 explained by the similar nitrogen contents observed in leaves across treatments with equal 409 fertilization (see Fig. S4 available as Supplementary Data at Tree Physiology Online), 410 since Chl $a+b$ is highly dependent on this variable (Niinemets 1997, Durand and 411 Goldstein 2001). On the other hand, a decrease on the ratio $\mathrm{Chl} a / \mathrm{Chl} b$ has frequently 
412 been used to inform about plant preferential relative investment on LHC over RC under

413 drought (García-Plazaola and Becerril 2000, Baquedano and Castillo 2006, Junker-Frohn

414 et al. 2019). However, in this experiment, we did not find a significant effect of drought

415 in this ratio (Fig. 5). Finally, the de-epoxidation state of xanthophylls $(A+Z / V+A+Z)$

416 increased under drought, particularly in immobilized leaflets. The xanthophyll cycle plays

417 a key role in leaf defence against the excess of light (Demmig-Adams and Adams 2006).

418 Moreover, not only light but also temperature can induce changes in this ratio and it has

419 been demonstrated that $\mathrm{A}+\mathrm{Z} / \mathrm{V}+\mathrm{A}+\mathrm{Z}$ can rise upon heating up of photosynthetic tissues

420 even in darkness (Fernández-Marín et al. 2011, Buchner et al. 2015). In this experiment,

421 immobilized leaflets probably suffered an increase on temperature at midday which can

422 partially explain the observed increase of $A+Z / V+A+Z$. These variations in pigment

423 ratios $(\mathrm{Neo}+\mathrm{Lut} / \beta-\mathrm{Car}$ and $\mathrm{A}+\mathrm{Z} / \mathrm{V}+\mathrm{A}+\mathrm{Z})$ concurred with a maximum quantum yield

424 decrease (Fig. 7), highlighting a greater need of tara to invest in thermal energy

425 dissipation in immobilized leaflets under severe drought, i.e., an increase in chemical

426 photoprotection when structural photoprotection (leaflet immobilization) was no longer

427 available. The significant relation found between $F_{v} / F_{m}$ and $A+Z / V+A+Z$ could indicate

428 that the decrease in the photochemical efficiency was partially due to an increase in the 429 energy dissipated through the xanthophylls (Martínez-Ferri et al. 2000), although this

430 relationship was weak, clearly suggesting a stronger photodamage effect induced by

431 drought (Fig. 4). However, as $\mathrm{F}_{\mathrm{v}} / \mathrm{F}_{\mathrm{m}}$ and $\mathrm{A}+\mathrm{Z} / \mathrm{V}+\mathrm{A}+\mathrm{Z}$ where measured at different times

432 of the day (predawn and midday, respectively), this correlation has to be cautiously 433 observed.

434 Leaflet closure was thus an efficient photoprotective strategy of tara that generated 435 benefits under drought stress, although at the same time, the reduction of light interception 436 entailed costs in terms of fewer carbon assimilation opportunities. Leaf reorientation to 
437 decrease intercepted light is a balance between photoprotection and carbon assimilation

438 (Valladares and Pugnaire 1999, Pastenes et al. 2005). Additionally, continued severe 439 drought stress led to a sharp decrease of carbon assimilation rate and photochemical 440 efficiency, and consequently to growth arrest.

\section{$441 \quad$ Photoprotection outcomes under drought relay on seedling provenance}

442 Under semi-controlled conditions, tara displayed a dehydration tolerant strategy i.e.

443 capable of decreasing water potential and stomatal conductance simultaneously to very 444 negative water potential levels (Figs. 3 and 4) (definition as in Volaire 2018), contrary to 445 that previously observed in the field in tara seedlings, where we reported early stomatal 446 closure and low water potential decrease i.e. dehydration avoidance (Balaguer et al. 447 2011). Gas exchange under drought and plant's dehydration strategies have been 448 extensively studied, with some species showing a dehydration tolerance strategy while 449 others have a dehydration avoiding one (e.g., Martínez-Ferri et al. 2000, Quero et al. 2011, 450 Katuwal et al. 2020). However, the combined dehydration avoidance/tolerance strategy 451 has been increasingly recognised in the literature (Berger et al. 2016, Volaire 2018), with 452 a respective prevalence of one or another depending on the plant status (e.g., nutritional 453 conditions, growth stage), and other external factors (e.g., stress intensity or frequency). 454 For example, Berger and Ludwig (2014) demonstrated a range of dehydration avoidance/tolerance strategies in Lupinus luteus L. depending on environmental conditions. It is possible that seedlings growing in a controlled environment have a better and consistent nutritional status than under more erratic field conditions, as pointed out

458 when we compared nitrogen leaf contents of the seedlings grown in greenhouse or in the 459 field (see Fig. S4 available as Supplementary Data at Tree Physiology Online). Our results 460 could be equally attributable to the plasticity of this species (Reynolds et al. 2018). In 461 fact, we observed a range of dehydration tolerances among tara provenances, with 
462 seedlings from the most xeric origins displaying the greatest abilities to withstand stress

463 (ATQ seedlings showed lower photoinhibition, highest overall water use efficiency and

464 kept their leaflets more open under drought, with lower assimilation costs).

465 Despite the low genetic variability of this species across its distribution range, evaluated 466 in adult trees (Balaguer et al. 2011), and according to our alternative hypothesis, our

467 results demonstrated clear differences in seedling performance depending on their 468 provenance, therefore pointing to local adaptation. This finding could be related to higher 469 genetic variability in the offspring compared to the adult trees, or to non-genetically based maternal effects (Galloway 2005). Although the genetic diversity of the seedlings used in

471 this experiment was not evaluated, it is possible that the isolation of some of the tara 472 populations have led to certain genetic differences (Rieseberg and Willis 2007), which 473 would deserve further analysis. On the other hand, trees with the same genotype can 474 produce offspring with different phenotypes displaying an enhanced fitness for the 475 particular environment where the mother was growing (Galloway 2005, Marshall and 476 Uller 2007). This maternal effect can be transmitted to the offspring through seed 477 characteristics, transmission of signals from the mother to the maturing zygote, and 478 inheritance of maternal epigenetic states (Roach and Wulff 1987, Penfield and 479 MacGregor 2017). This has been previously demonstrated in other tree species, such as 480 Quercus ilex, where common garden experiments showed differences among 481 provenances in the photoprotective mechanisms of seedlings due to local adaptation 482 (Camarero et al. 2012).

483 As predicted under the hypothesis of local adaptation, tara responses to avoid 484 photodamage under water shortage had different physiological consequences depending 485 on the seed origin. We expected that tara provenances from areas with higher water 486 availability would completely close their leaflets and stomata under water stress to 
preserve their photosynthetic apparatus but with a high assimilation cost. This prediction

488 was confirmed and the two provenances with wettest conditions (POL, and especially 489 AND) tightly closed their leaflets under severe drought (Fig. 3), with a higher assimilation cost (stronger negative correlation between the assimilation rate and the leaflet angle, Fig. 7). Moreover, leaflet closure proved to be an effective mechanism for recovering net 492 carbon assimilation in the provenances with driest habitats (JER, ATQ) (i.e., higher 493 assimilation rates in mobile than immobilized leaflets after drought, Fig. 4) but not in 494 POL and AND, emphasizing the higher assimilation cost for the wettest habitats. 495 Additionally, the high precipitation seasonality of AND may have favoured a water 496 saving strategy of seedlings, tightly closing stomata early and with a fast recovery during 497 rewetting, as previously observed in Eucalyptus microtheca F.Muell. provenances from 498 highly seasonal areas ( $\mathrm{Li}$ et al. 2000). Seedlings from the provenance with driest 499 conditions, ATQ, showed in general higher ability to cope with drought. They kept their 500 leaflets more open under severe drought, with lower assimilation costs, showed low 501 photoinhibition and also had the highest overall water use efficiency (Figs. 3 and 4).

502 These results are in accordance to other studies, where tree provenances from more xeric

503 locations showed a higher physiological ability to cope with drought (Nguyen-Queyrens 504 and Bouchet-Lannat 2003, López et al. 2009, Corcuera et al. 2012, Ying et al. 2015, 505 Matías et al. 2019).

506 We also predicted that combined drought and light stress would imbalance the ratios 507 between different photosynthetic pigments preferentially in provenances from wetter 508 areas, promoting the investment in energy dissipation pigments to avoid photodamage. 509 This hypothesis was also confirmed, as POL and particularly AND (wettest) showed the 510 biggest changes in the pigment balances related to chemical photoprotection (Neo+Lut/ $\beta$ -

511 Car and $A+Z / V+A+Z$ ratios, Fig. 5). Changes in photosynthetic pigment ratios under 
512 water deficiency depending on seed provenance have been previously reported for other

513 tree species, such as Douglas-fir (Junker et al. 2017) or Quercus spp. (Ramírez-Valiente

514 et al. 2015). Additionally, provenances from wetter habitats showed the highest relative

515 growth under not water-limiting conditions and the highest reduction of this rate during

516 water stress (Fig. 8), indicating their high morphological sensibility to drought, as

517 observed in provenances with high precipitations of other tree species such as

518 Pseudotsuga menziesii (Mirb.) (Eilmann et al. 2013) or Arbutus unedo L. (Vasques et al.

519 2013). This fact also highlights the trade-off between water-acquisition (i.e., growth) and

520 water-conservation (i.e., drought survival) (Volaire 2018).

521 The extraordinary capacity of local adaptation to dry conditions of tara could be at the

522 origin of the ecological success of this species (Gagnon et al. 2019), and might favour its

523 persistence under the predicted drier and increasingly more unforeseeable climate

524 (Alberto et al. 2013, Valladares et al. 2014). This can be crucial for the success of

525 restoration actions aiming to keep this keystone species in areas such as the fog forests,

526 and to give economic support to local communities in wide areas of South America

527 (Larrea 2011, Cordero, Jiménez, et al. 2016, Sotomayor and Drezner 2019).

528 Conclusions

529 This study evidences the different mechanisms of tara to cope with water and light stress,

530 under semi-controlled conditions. Leaflet closure in tara has a double benefit under water

531 stress, since it diminishes the evaporative demand and avoids photodamage (structural

532 photoprotection), although it also entails costs by reducing the carbon assimilation

533 opportunities. Supporting our alternative hypothesis of a local adaptation, these responses

534 depended on the seed origin, with seedlings from provenances with the most xeric

535 conditions (particularly Atiquipa) displaying the highest capacity to withstand drought.

536 Thus, the observed intraspecific variation is likely the result of local adaptation, which 
537 represents that different photoprotective strategies were revealed useful in different

538 environments. This plasticity on tara response to environmental stress allows it to thrive 539 in localities with contrasting water availability. The results from this study allow us to 540 better understand the ecology and performance of tara under different climatic conditions

541 and future global change scenarios. They can be also greatly helpful to plan efficient

542 ecological restoration or reforestation projects with tara, a keystone legume tree in the dry

543 forests of South America.

544 


\section{Data and Materials availability}

546 All data from this paper will be available to other academic researchers upon reasonable 547 request.

\section{Supplementary data}

550 Additional supporting information may be found in the online version of this article:

551 Fig. S1 Evolution of soil water content along the experimental time.

552 Fig. S2 Effects of drought on seedling growth rate.

553 Fig. S3 Effects of drought and leaflet immobilization on the photosynthetic pigments of 554 tara seedlings.

555 Fig. S4 Leaf nitrogen content of tara under field and greenhouse conditions.

556 Table S1 Statistical summary of the main and interactive effects of the factors 557 provenance, drought, leaflet immobilization and time on the physiological and 558 morphological variables of tara seedlings.

560 Conflict of interest

$561 \quad$ None declared.

562

563 Funding

564 This work was supported by the SEGARNIEBLA project founded by BBVA Foundation, 565 and grants from Comunidad de Madrid (S2009/AMB-1511) and MINECO (AGL2013566 40758-R). IC was supported by the Autonomic Council of Education, Comunidad de 567 Madrid (Spain) (CPI/0243/2008), a Ramon Areces Foundation research grant, and a 568 BBSRC Discovery Fellowship (BB/S010661/1). 


\section{Acknowledgments}

570 We gratefully acknowledge Blanca Santamaría-Pérez, Manuela López Valero and Diego

571 Abad Martín for their assistance in the greenhouse. We also acknowledge Luis Villegas

572 Paredes, Percy Jiménez, Luis Albán Contreras and José Manuel Serrano for their

573 assistance collecting tara seeds. We finally thank Arthur Broadbent and David Johnson

574 for their valuable comments on the manuscript. We thank the anonymous reviewers for

575 improving a previous version of the manuscript.

576 The experiment was carried out in the greenhouse facilities of the Institute of Agricultural

577 Sciences, Spanish National Research Council (ICA-CSIC), Madrid, Spain.

578

579 Authors' contributions

580 IC, MDJ, JAD, LB, JJP and AR contributed to the design of the experiments. IC, MDJ

581 and JAD collected the seeds in Peru. IC performed all experiments and measurements,

582 eventually assisted by JAD and MDJ. IC, MDJ, JAD, LB, JJP and AR analysed and

583 interpreted data. IC, MDJ, JAD, JJP and AR contributed to the writing of the manuscript. 


\section{References}

586 Alberto FJ, Aitken SN, Alía R, González-Martínez SC, Hänninen H, Kremer A, Lefèvre

587 F, Lenormand T, Yeaman S, Whetten R, Savolainen O (2013) Potential for 588 evolutionary responses to climate change - evidence from tree populations. Glob $589 \quad$ Chang Biol 19:1645-1661.

590 Arena C, Vitale L, De Santo AV (2008) Paraheliotropism in Robinia pseudoacacia L.: an 591 efficient strategy to optimise photosynthetic performance under natural 592 environmental conditions. Plant Biol 10:194-201.

593 Arróniz-Crespo M, Leake JR, Horton P, Phoenix GK (2008) Bryophyte physiological 594 responses to, and recovery from, long-term nitrogen deposition and phosphorus 595 fertilisation in acidic grassland. New Phytol 180:864-874.

596 Balaguer L, Arroyo-García R, Jiménez P, Jiménez MD, Villegas L, Cordero I, Rubio de 597 Casas R, Fernández-Delgado R, Ron ME, Manrique E, Vargas P, Cano E, Pueyo JJ, 598 Aronson J (2011) Forest restoration in a fog oasis: evidence indicates need for 599 cultural awareness in constructing the reference. PLoS One 6:e23004.

600 Baquedano FJ, Castillo FJ (2006) Comparative ecophysiological effects of drought on 601 seedlings of the Mediterranean water-saver Pinus halepensis and water-spenders 602 Quercus coccifera and Quercus ilex. Trees 20:689-700.

603 Berger JD, Ludwig C (2014) Contrasting adaptive strategies to terminal drought-stress 604 gradients in Mediterranean legumes: phenology, productivity, and water relations in 605 wild and domesticated Lupinus luteus L. J Exp Bot 65:6219-6229.

606 Berger J, Palta J, Vadez V (2016) Review: An integrated framework for crop adaptation 607 to dry environments: Responses to transient and terminal drought. Plant Sci 253:58608 67.

609 Bouvet M, Hoepffner N, Dowell MD (2002) Parameterization of a spectral solar 

irradiance model for the global ocean using multiple satellite sensors. J Geophys Res 107:3215.

612 Buchner O, Stoll M, Karadar M, Kranner I, Neuner G (2015) Application of heat stress 613 in situ demonstrates a protective role of irradiation on photosynthetic performance 614 in alpine plants. Plant, Cell Environ 38:812-826.

615 Camarero JJ, Olano JM, Arroyo Alfaro SJ, Fernández-Marín B, Becerril JM, García616 Plazaola JI (2012) Photoprotection mechanisms in Quercus ilex under contrasting $617 \quad$ climatic conditions. Flora 207:557-564.

618 Canziani Amico J (2002) Las Lomas de Atiquipa: un caso de paisaje cultural en la costa 619 desértica del sur del Perú. In: Mujica E (ed) Paisajes culturales en los Andes: 620 memoria narrativa, casos de estudio, conclusiones y recomendaciones de la Reunión de expertos, Arequipa y Chivay, Perú. UNESCO, Lima, Peru, pp 169-190.

Chirino E, Ruiz-Yanetti S, Vilagrosa A, Mera X, Espinoza M, Lozano P (2017) Morphofunctional traits and plant response to drought conditions in seedlings of six native species of Ecuadorian Ecosystems. Flora 233:58-67.

Corcuera L, Gil-Pelegrín E, Notivol E, Tognetti R (2012) Differences in hydraulic architecture between mesic and xeric Pinus pinaster populations at the seedling stage. Tree Physiol 32:1442-1457.

Cordero I, Jiménez MD, Delgado JA, Villegas L, Balaguer L (2016) Spatial and demographic structure of tara stands (Caesalpinia spinosa) in Peru: influence of present and past forest management. For Ecol Manage 377:71-82.

631 Cordero I, Ruiz-Díez B, Balaguer L, Richter A, Pueyo JJ, Rincón A (2017) Rhizospheric microbial community of Caesalpinia spinosa (Mol.) Kuntze in conserved and deforested zones of the Atiquipa fog forest in Peru. Appl Soil Ecol 114:132-141.

634 Cordero I, Ruiz-Díez B, Coba de la Peña T, Balaguer L, Lucas MM, Rincón A, Pueyo JJ 
(2016) Rhizobial diversity, symbiotic effectiveness and structure of nodules of Vachellia macracantha. Soil Biol Biochem 96:39-54.

Demmig-Adams B, Adams WW (2006) Photoprotection in an ecological context: the remarkable complexity of thermal energy dissipation. New Phytol 172:11-21.

Díaz S, Kattge J, Cornelissen JHC, Wright IJ, Lavorel S, Dray S, Reu B, Kleyer M, Wirth C, Colin Prentice I, Garnier E, Bönisch G, Westoby M, Poorter H, Reich PB, Moles AT, Dickie J, Gillison AN, Zanne AE, Chave J, Joseph Wright S, Sheremet Ev SN, Jactel H, Baraloto C, Cerabolini B, Pierce S, Shipley B, Kirkup D, Casanoves F, Joswig JS, Günther A, Falczuk V, Rüger N, Mahecha MD, Gorné LD (2016) The global spectrum of plant form and function. Nature 529:167-171.

Dombroski JLD, Praxedes SC, de Freitas RMO, Pontes FM (2011) Water relations of Caatinga trees in the dry season. South African J Bot 77:430-434.

Durand LZ, Goldstein G (2001) Photo-synthesis, photoinhibition, and nitrogen use efficiency in native and invasive tree ferns in Hawaii. Oecologia 126:345-354.

Eilmann B, de Vries SMG, den Ouden J, Mohren GMJ, Sauren P, Sass-Klaassen U (2013) Origin matters! Difference in drought tolerance and productivity of coastal Douglasfir (Pseudotsuga menziesii (Mirb.)) provenances. For Ecol Manage 302:133-143.

Esteban R, Barrutia O, Artetxe U, Fernández-Marín B, Hernández A, García-Plazaola JI (2015) Internal and external factors affecting photosynthetic pigment composition in plants: a meta-analytical approach. New Phytol 206:268-280.

Fernández-Marín B, Míguez F, Becerril JM, García-Plazaola JI (2011) Activation of violaxanthin cycle in darkness is a common response to different abiotic stresses: a case study in Pelvetia canaliculata. BMC Plant Biol 11:181. 
661 Galloway LF (2005) Maternal effects provide phenotypic adaptation to local environmental conditions. New Phytol 166:93-100.

663 García-Plazaola JI, Becerril JM (2000) Effects of drought on photoprotective mechanisms 664 in European beech (Fagus sylvatica L.) seedlings from different provenances. Trees $14: 485-490$.

Genty B, Briantais JM, Baker NR (1989) The relationship between the quantum yield of photosynthetic electron transport and quenching of chlorophyll fluorescence. Biochim Biophys Acta 990:87-92.

Lo Gullo MA, Salleo S, Rosso R, Trifilò P (2003) Drought resistance of 2-year-old saplings of Mediterranean forest trees in the field: relations between water relations, hydraulics and productivity. Plant Soil 250:259-272.

Hijmans RJ (2014) raster: Geographic data analysis and modeling. R package version

Huang W, Zhang J, Zhang S, Hu H (2014) Evidence for the regulation of leaf movement by photosystem II activity. Environ Exp Bot 107:167-172.

INRENA (1995) Mapa Ecológico del Perú. Instituto de los Recursos Naturales, 677 Ministerio de Agricultura, República del Perú, Lima, Peru. http://es.scribd.com/doc/32987194/INRENA-mapa-ecologico I, II and III to the Fifth Assessment Report of the Intergovernmental Panel on 682 Junker-Frohn LV, Kleiber A, Jansen K, Gessler A, Kreuzwieser J, Ensminger I (2019) 683 Differences in isoprenoid-mediated energy dissipation pathways between coastal and interior Douglas-fir seedlings in response to drought. Tree Physiol 39:1750- 
686 Junker LV, Kleiber A, Jansen K, Wildhagen H, Hess M, Kayler Z, Kammerer B, 687 Schnitzler JP, Kreuzwieser J, Gessler A, Ensminger I (2017) Variation in short-term 688 and long-term responses of photosynthesis and isoprenoid-mediated photoprotection 689 to soil water availability in four Douglas-fir provenances. Sci Rep 7:40145.

690 Kao WY, Forseth IN (1992) Responses of gas exchange and phototropic leaf orientation 691 in soybean to soil water availability, leaf water potential, air temperature, and 692 photosynthetic photon flux. Environ Exp Bot 32:153-161.

693 Karabourniotis G, Liakopoulos G, Nikolopoulos D, Bresta P, Stavroulaki V, Sumbele S 694 (2014) 'Carbon gain vs. water saving, growth vs. defence': two dilemmas with 695 soluble phenolics as a joker. Plant Sci 227:21-27.

696 Katuwal KB, Schwartz B, Jespersen D (2020) Desiccation avoidance and drought 697 tolerance strategies in bermudagrasses. Environ Exp Bot 171:103947.

de la Cruz Lapa P (2004) Aprovechamiento integral y racional de la tara Caesalpinia spinosa - Caesalpinia tinctoria. Rev del Inst Investig FIGMMG 7:64-73.

700 Larrea M (2011) La tara, guarango o taya (Caesalpinia spinosa) en la Región Andina: 701 criterios ambientales para la sustentabilidad de su aprovechamiento y manejo en 702 Bolivia, Ecuador y Perú. ECOBONA, Serie de Capacitación No. 5. Programa 703 Regional ECOBONA-INTERCOOPER, Quito, Peru.

704 Lawlor DW, Tezara W (2009) Causes of decreased photosynthetic rate and metabolic 705 capacity in water-deficient leaf cells: a critical evaluation of mechanisms and 706 integration of processes. Ann Bot 103:561-579.

707 Lewis G, Schrire B, Mackinder B, Lock M (eds) (2005) Legumes of the world. Royal $708 \quad$ Botanic Gardens, Kew.

709 Li C, Berninger F, Koskela J, Sonninen E (2000) Drought responses of Eucalyptus 

microtheca provenances depend on seasonality of rainfall in their place of origin. Funct Plant Biol 27:231-238.

Llorens L, Peñuelas J, Filella I (2003) Diurnal and seasonal variations in the photosynthetic performance and water relations of two co-occurring Mediterranean shrubs, Erica multiflora and Globularia alypum. Physiol Plant 118:84-95.

López R, Rodríguez-Calcerrada J, Gil L (2009) Physiological and morphological response to water deficit in seedlings of five provenances of Pinus canariensis: potential to detect variation in drought-tolerance. Trees 23:509-519.

Marshall DJ, Uller T (2007) When is a maternal effect adaptive? Oikos 116:1957-1963.

Martínez-Ferri E, Balaguer L, Valladares F, Chico JM, Manrique E (2000) Energy dissipation in drought-avoiding and drought-tolerant tree species at midday during the Mediterranean summer. Tree Physiol 20:131-138.

Masuda T, Polle EW, Melis A (2002) Biosynthesis and distribution of chlorophyll among the photosystems during recovery of the green alga Dunaliella salina from irradiance stress. Plant Physiol 128:603-614.

Matías L, Pérez-Ramos IM, Gómez-Aparicio L (2019) Are northern-edge populations of J, West A, Williams DG, Yepez E a. (2008) Mechanisms of plant survival and mortality during drought: why do some plants survive while others succumb to drought? New Phytol 178:719-739.

Ministry of Agriculture and Livestock (1978) Mapa Ecológico del Ecuador. Programa Nacional de Regionalización Agraria PRONAREG., Ecuador.

734 Nguyen-Queyrens A, Bouchet-Lannat F (2003) Osmotic adjustment in three-year-old 
seedlings of five provenances of maritime pine (Pinus pinaster) in response to drought. Tree Physiol 23:397-404.

737

738

739

740

741

742

743

744

745

746

747

748

749

750

751

752

753

754

755

756

757

758

759

Niinemets Ü (1997) Role of foliar nitrogen in light harvesting and shade tolerance of four temperate deciduous woody species. Funct Ecol 11:518-531.

Ochoa-Hueso R, Paradela C, Pérez-Corona ME, Manrique E (2014) Pigment ratios of the Mediterranean bryophyte Pleurochaete squarrosa respond to simulated nitrogen deposition. In: Sutton M, Mason K, Sheppard L, Sverdrup H, Haeuber R, Hicks W (eds) Nitrogen Deposition, Critical Loads and Biodiversity. Springer, Dordrecht, pp 207-216.

Oliveira G, Peñuelas J (2002) Comparative protective strategies of Cistus albidus and Quercus ilex facing photoinhibitory winter conditions. Environ Exp Bot 47:281289.

Osmond CB (1994) What is photoinhibition? Some insights from comparison of shade and sun plants. In: Baker NR, Bowyer JR (eds) Photoinhibition of Photosynthesis: from Molecular Mechanisms to the Field. BIOS Scientific Publishers, Oxford, Reino Unido, pp 1-24.

Pastenes C, Pimentel P, Lillo J (2005) Leaf movements and photoinhibition in relation to water stress in field-grown beans. J Exp Bot 56:425-433.

Penfield S, MacGregor DR (2017) Effects of environmental variation during seed production on seed dormancy and germination. J Exp Bot 68:819-825.

Pineda-García F, Paz H, Meinzer FC, Angeles G (2015) Exploiting water versus tolerating drought: Water-use strategies of trees in a secondary successional tropical dry forest. Tree Physiol 36:208-217.

Quero JL, Sterck FJ, Martínez-Vilalta J, Villar R (2011) Water-use strategies of six coexisting Mediterranean woody species during a summer drought. Oecologia 166:45- 
761 Ramírez-Valiente JA, Koehler K, Cavender-Bares J (2015) Climatic origins predict variation in photoprotective leaf pigments in response to drought and low temperatures in live oaks (Quercus series Virentes). Tree Physiol 35:521-534.

Ramírez DA, Balaguer L, Mancilla R, González V, Coaguila D, Talavera C, Villegas L, Ortega A, Jiménez P, Moreno JM (2012) Leaf-trait responses to irrigation of the endemic fog-oasis tree Myrcianthes ferreyrae: can a fog specialist benefit from regular watering? Tree Physiol 32:65-73.

Raven JA (2011) The cost of photoinhibition. Physiol Plant 142:87-104.

Reynolds VA, Anderegg LDL, Loy X, HilleRisLambers J, Mayfield MM (2018) Unexpected drought resistance strategies in seedlings of four Brachychiton species. Tree Physiol 38:664-677.

Rieseberg LH, Willis JH (2007) Plant Speciation. Science (80- ) 317:910-914.

Roach DA, Wulff RD (1987) Maternal effects in plants. Annu Rev Ecol Syst 18:209235.

Sotomayor DA, Drezner TD (2019) Dominant plants alter the microclimate along a fog gradient in the Atacama Desert. Plant Ecol 220:417-432.

Tognetti R (2015) Trees harvesting the clouds: Fog nets threatened by climate change. Tree Physiol 35:921-924.

Valladares F, Matesanz S, Guilhaumon F, Araujo MB, Balaguer L, Benito-Garzon M, Cornwell W, Gianoli E, van Kleunen M, Naya DE, Nicotra AB, Poorter H, Zavala MA (2014) The effects of phenotypic plasticity and local adaptation on forecasts of species range shifts under climate change. Ecol Lett 17:1351-1364. 
786 Vasques A, Chirino E, Vilagrosa A, Vallejo VR, Keizer JJ (2013) The role of seed provenance in the early development of Arbutus unedo seedlings under contrasting watering conditions. Environ Exp Bot 96:11-19.

789 Volaire F (2018) A unified framework of plant adaptive strategies to drought: Crossing $790 \quad$ scales and disciplines. Glob Chang Biol 24:2929-2938.

791 Wennersten L, Forsman A (2012) Population-level consequences of polymorphism, 792 plasticity and randomized phenotype switching: A review of predictions. Biol Rev $793 \quad 87: 756-767$.

794 Ying YQ, Song LL, Jacobs DF, Mei L, Liu P, Jin SH, Wu JS (2015) Physiological response to drought stress in Camptotheca acuminata seedlings from two provenances. Front Plant Sci 6:1-8. 
799 Fig. 1 Latitudinal gradient and climatic diagrams of the different provenances of tara

800 (Caesalpinia spinosa). Climatic and bioclimatic data were obtained from WorldClim 801 database (1950-2000) (Hijmans 2014). Solid bars indicate mean precipitation and the 802 black line represents mean temperature. In Atiquipa, fog collection data are included 803 (slashed bars), monthly means and standard error of five consecutive years (2003-2007) 804 (Cordero, Jiménez, et al. 2016). Bioclimatic variables: annual water input (WI), 805 precipitation seasonality (S) and precipitation of the wettest quarter (PWQ). m asl: meters

806 above sea level. ${ }^{1,2}$ Holdridge life zone: ${ }^{1}$ Ministry of Agriculture and Livestock (1978), $807 \quad{ }^{2}$ INRENA (1995).

808

809 Fig. 2 (a) Mature tara pinnae (circles) and leaflets (arrows). (b) Immobilized leaflets 810 (white arrow) in a mature tara pinna from a drought exposed seedling.

812 Fig. 3 Effects of drought on (a) midday water potential ( $\left.\Psi_{\text {mid }}\right)$ and (b) leaflet's angle at 813 midday of different provenances of Caesalpinia spinosa $(\mathrm{AND}=$ Andurco, $\mathrm{POL}=$ Polán, 814 JER = Jerusalem, ATQ = Atiquipa). In each graphic, the dashed vertical line indicates the 815 end of drought and the start of rewetting (day 22). Grey diamonds = control, dark grey 816 squares $=$ moderate drought D1; black triangles $=$ severe drought D2. In (b) filled lines $=$ 817 mobile leaflets; dashed lines $=$ immobilized leaflets. Values $=$ mean \pm standard error; $\mathrm{n}=8$.

818 Data were analysed by linear mixed models with the seedling as random factor. At each 819 day, asterisks indicate significant drought effect, and dots and crosses indicate significant 820 effects of leaflet immobilization and its interaction with drought, respectively $(\mathrm{p}<0.05)$.

821 Values in the top of each graph indicate overall marginal means \pm standard error of the 822 factor provenance in the models (Table S1) for that variable, and in each case, different 
823 capital letters denote significant differences across tara provenances according to

824 Bonferroni test $(\mathrm{p}<0.05)$.

825

826 Fig. 4 Physiological response of Caesalpinia spinosa to drought (light grey diamonds =

827 control, dark grey squares = moderate drought D1; black triangles = severe drought D2),

828 leaflet immobilization (filled lines = mobile; dashed lines = immobilized) and time,

829 separately analysed by linear mixed models for different seed provenances (AND =

830 Andurco, POL = Polán, JER = Jerusalem, ATQ = Atiquipa). Dashed vertical line indicates

831 the end of the drought and the start of the rewetting (day 22). (a) Net carbon assimilation

832 (A), (b) stomatal conductance $\left(g_{\mathrm{s}}\right)$, (c) water use efficiency (WUE), and (d) maximum

833 quantum yield of photosystem II $\left(\mathrm{F}_{\mathrm{v}} / \mathrm{F}_{\mathrm{m}}\right)$. Values $=$ mean \pm standard error; $n=4(n=8$ for

$\left.834 \mathrm{~F}_{\mathrm{v}} / \mathrm{F}_{\mathrm{m}}\right)$. At each day, asterisks, dots and crosses indicate significant effects of the factors

835 drought, immobilization and their interaction, respectively $(\mathrm{p}<0.05)$. Values in the top of

836 each graph are overall marginal means \pm standard error, when including the factor

837 provenance in the models (Table S1), and different capital letters denote significant

838 differences among treatments. In all cases, differences between treatments were separated

839 by the Bonferroni test $(\mathrm{p}<0.05)$.

840

841 Fig. 5 Chemical photoprotection of Caesalpinia spinosa five days before the end of the

842 drought period, testing the factors drought (D) (white $=$ control, grey $=$ moderate drought

843 D1; black = severe drought D2) and leaflet immobilization (I) (mobile or immobilized)

844 for each seed provenance $(\mathrm{AND}=$ Andurco, $\mathrm{POL}=$ Polán, JER $=$ Jerusalem, $\mathrm{ATQ}=$

845 Atiquipa). Data were analysed by linear mixed models with the seedling as random factor.

$846 * \mathrm{p}<0.05 ; * * \mathrm{p}<0.01 ; * * * \mathrm{p}<0.001$. (a) ratio (neoxanthin + lutein) / $\beta$-carotene; (b) de-

847 epoxidation state $(\mathrm{A}=$ antheraxanthin, $\mathrm{Z}=$ zeaxanthin; $\mathrm{V}=$ violaxanthin); (c) Chlorophyll 
$848 a$ and $b$ content $\left(\mu \mathrm{mol} \mathrm{m} \mathrm{m}^{-2}\right)$; (d) Chlorophyll $a / b$ ratio. Values $=$ mean \pm standard error;

$849 \mathrm{n}=4$. Within each immobilization treatment, different lower-case letters denote significant

850 differences among drought treatments. For a given drought treatment, asterisks indicate

851 significant differences due to leaflet immobilization. Values in the top of each graph are

852 overall marginal means \pm standard error, when including the factor provenance in the

853 models (Table S1), and similar capital letters denote no significant differences among

854 treatments. In all cases, differences between treatments were separated by the Bonferroni 855 test $(\mathrm{p}<0.05)$.

856

857 Fig 6 Benefits of leaflet closure under severe drought at the end of the drought period, 858 expressed as relative change ratio of severe drought (D2) in mobile and immobilized 859 leaflets compared to well-watered control mobile leaflets. Dashed line indicates no 860 difference with the control. Values above and below that line correspond to respective 861 increases or decreases of that variable compared to the control. Significance of the 862 differences between mobilization/immobilized treatments for the same variables are 863 shown: $* \mathrm{p}<0.05 ; * * \mathrm{p}<0.01 ; * * * \mathrm{p}<0.001$. Neo+Lut/ $\beta-$ Car $=$ ratio (neoxanthin + lutein) /

$864 \beta$-carotene; $\mathrm{A}+\mathrm{Z} / \mathrm{V}+\mathrm{A}+\mathrm{Z}=$ de-epoxidation state $(\mathrm{A}=$ antheraxanthin, $\mathrm{Z}=$ zeaxanthin; $\mathrm{V}=$ 865 violaxanthin); $\mathrm{A}=$ Net carbon assimilation; $\mathrm{g}=$ stomatal conductance; WUE $=$ water use 866 efficiency; $F_{v} / F_{m}=$ maximum quantum yield of photosystem II.. Values $=$ mean \pm 867 standard error; $n=16\left(n=32\right.$ for $\left.F_{v} / F_{m}\right)$.

869 Fig. 7 Relationships between physiological variables of Caesalpinia spinosa seedlings at 870 the end of the drought (day 22). Different colours and shapes indicate different 871 provenances: Andurco AND (filled black circle, black line), Polán POL (filled grey 872 square, grey line), Jerusalem JER (open grey triangle, dashed grey line) and Atiquipa 
873 ATQ (open black diamond, dashed black line). Mobile leaflet data were used for

874 regressions including the leaflet angle (a, b, c, d), and all data (mobile and immobilized 875 leaflets) for the rest of analyses. For each provenance, when significant, $\mathrm{R}^{2}$ and 876 signification value $\left(* \mathrm{p}<0.05 ;{ }^{* *} \mathrm{p}<0.01\right.$; $\left.* * * \mathrm{p}<0.001\right)$ of the linear $(\mathrm{a}, \mathrm{b}, \mathrm{c}, \mathrm{e})$ or quadratic

877 regressions $(\mathrm{d}, \mathrm{f})$ are shown. Non-significant regression lines/curves are not drawn. $\Psi_{\text {mid: }}$

878 midday water potential; E: transpiration rate, A: net carbon assimilation, $\mathrm{F}_{\mathrm{v}} / \mathrm{F}$ : maximum 879 quantum yield of PSII, WUE: water use efficiency, Neo+Lut/ $\beta$-Car: ratio (neoxanthin + 880 lutein) / $\beta$-carotene, $\mathrm{A}+\mathrm{Z} / \mathrm{V}+\mathrm{A}+\mathrm{Z}$ : de-epoxidation state.

881

882 Fig. 8 Correlations between physiological-morphological traits of Caesalpinia spinosa 883 seedlings and the climatic variables of the sites of provenance: Andurco AND (filled 884 circle), Polán POL (filled square), Jerusalem JER (open triangle) and Atiquipa ATQ 885 (open diamond). Blue $=$ well-watered control, red $=$ severe drought D2. Data from days

88617 and 22. Data are mean \pm standard error. $\Psi_{\text {mid: }}$ midday water potential; $g_{\text {s }}$ : stomatal 887 conductance; WUE: water use efficiency; $\mathrm{F}_{\mathrm{v}} / \mathrm{F}_{\mathrm{m}}$ : Maximum quantum yield of PSII. 888 Reduction of RG h: difference of the relative growth in height in the treatment of severe 889 drought compared with the control. Bioclimatic variables (annual water input and 890 precipitation seasonality) were extracted from the WorldClim database (Hijmans 2014) 891 and the number of dry months was calculated following the Gaussen index, which defines 892 a dry month depending on the mean precipitation $(\mathrm{P})$ and temperature $(\mathrm{T})$ when $\mathrm{P}<2 \mathrm{~T}$. In 893 each graph, the value of the Spearman correlation coefficient and its significance $\left({ }^{\text {ns }}=\right.$ not 894 significant; $* \mathrm{p}<0.05 ; * * \mathrm{p}<0.01 ; * * * \mathrm{p}<0.001)$ are shown. 


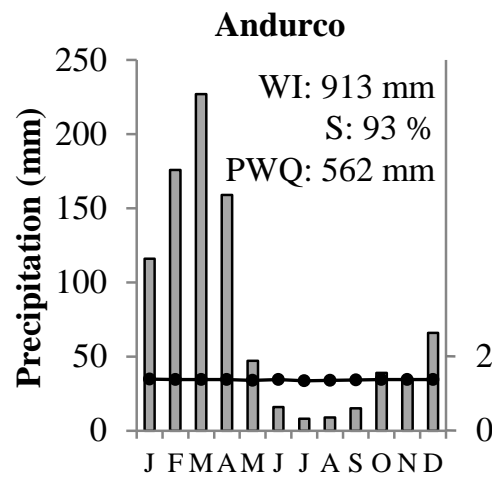

446’22”S; 79॰42’13”W

$2200 \mathrm{~m}$ asl

Lower montane tropical dry forest ${ }^{2}$

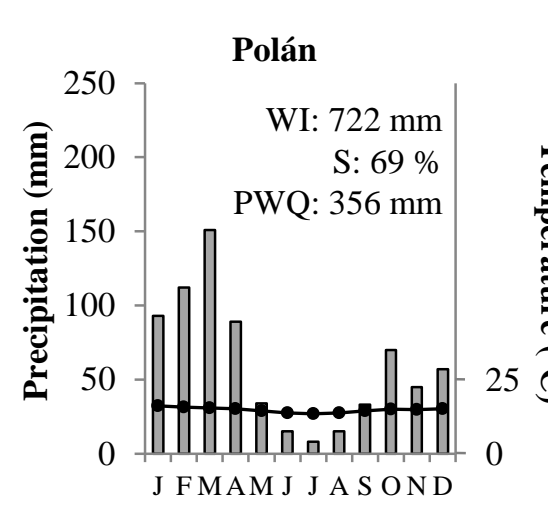

709'04"S; 7846’43”W $2300 \mathrm{~m}$ asl

Lower montane tropical dry forest ${ }^{2}$
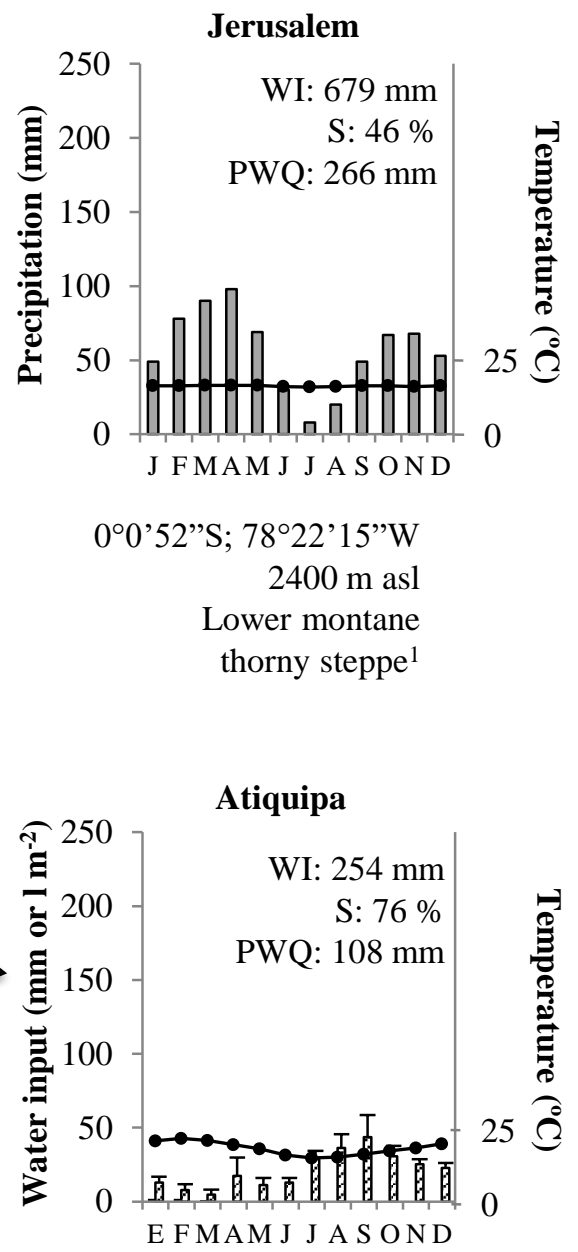

$15^{\circ} 45^{\prime} 40^{\prime \prime} \mathrm{S} ; 7^{\circ} 22^{\prime} 14^{\prime \prime} \mathrm{W}$

$1000 \mathrm{~m}$ asl

Warm-temperate subtropical dessert scrub (lomas) / Fog forest ${ }^{2}$ 
Figure 2

(a)

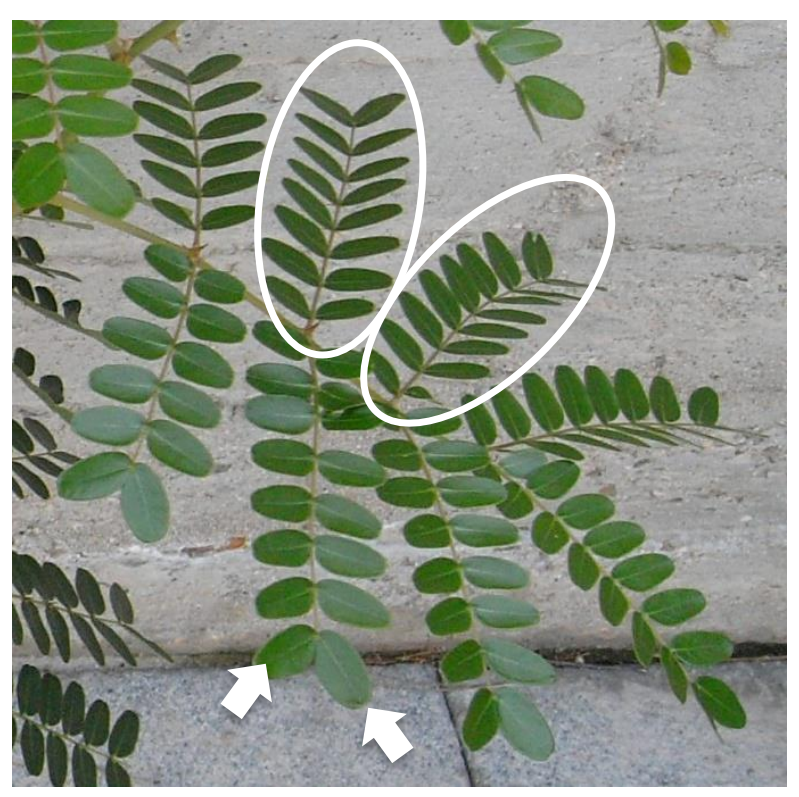

(b)

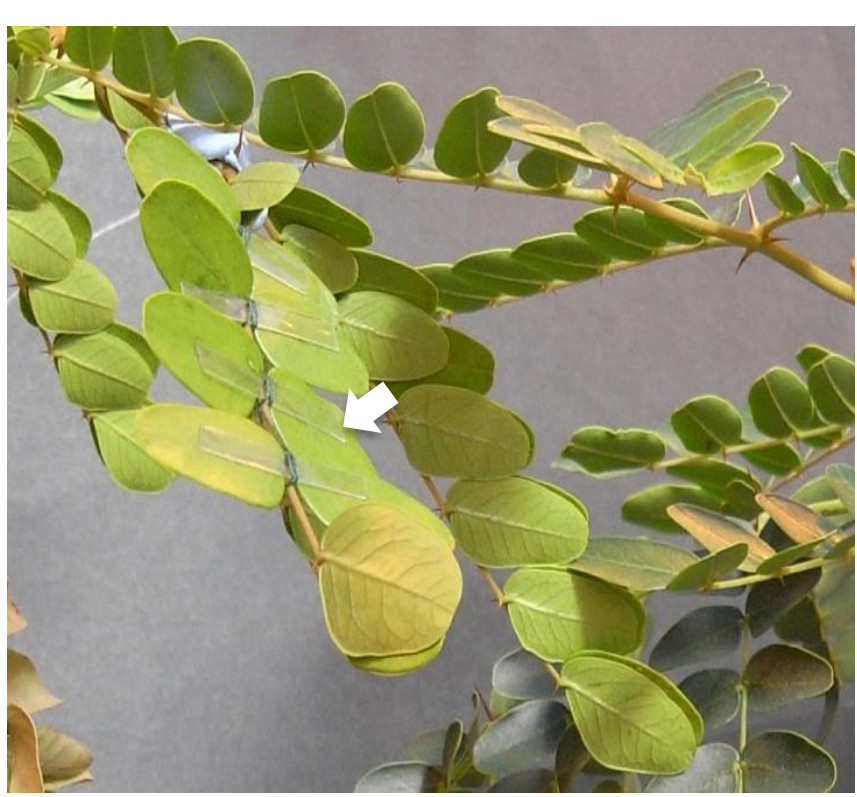


0000 AND

(a)

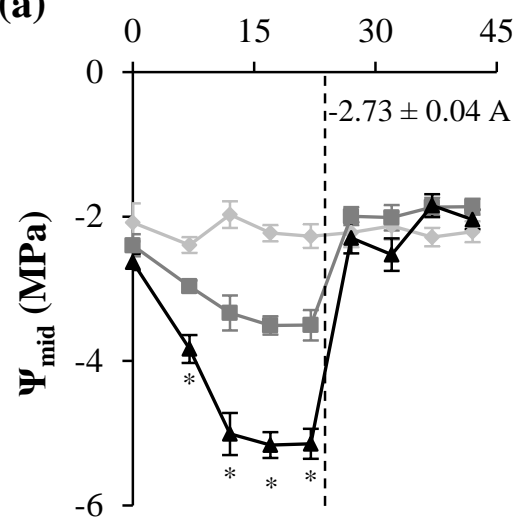

(b)

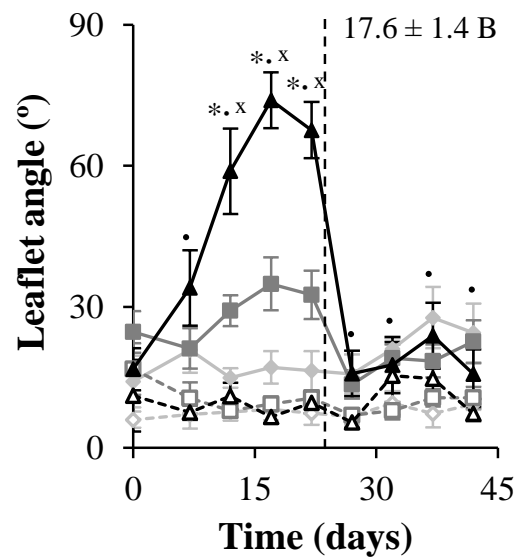

POL
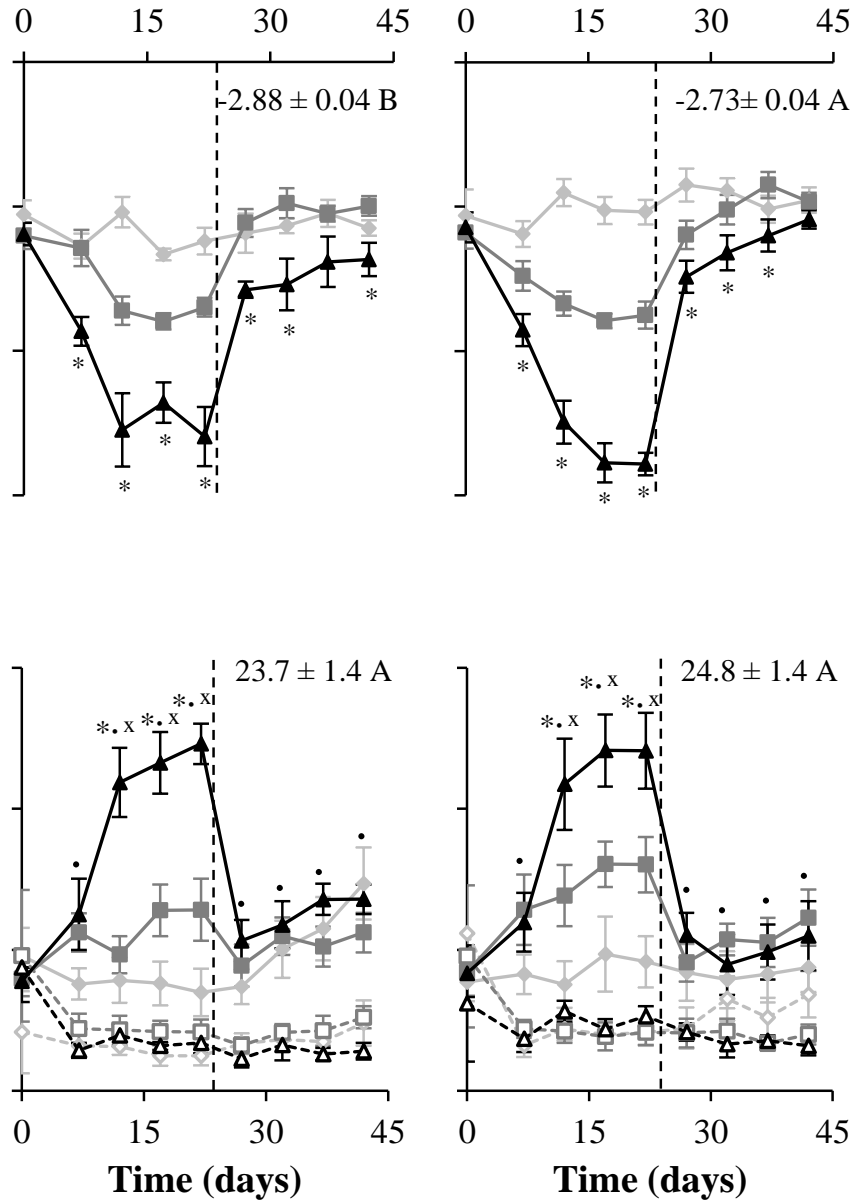
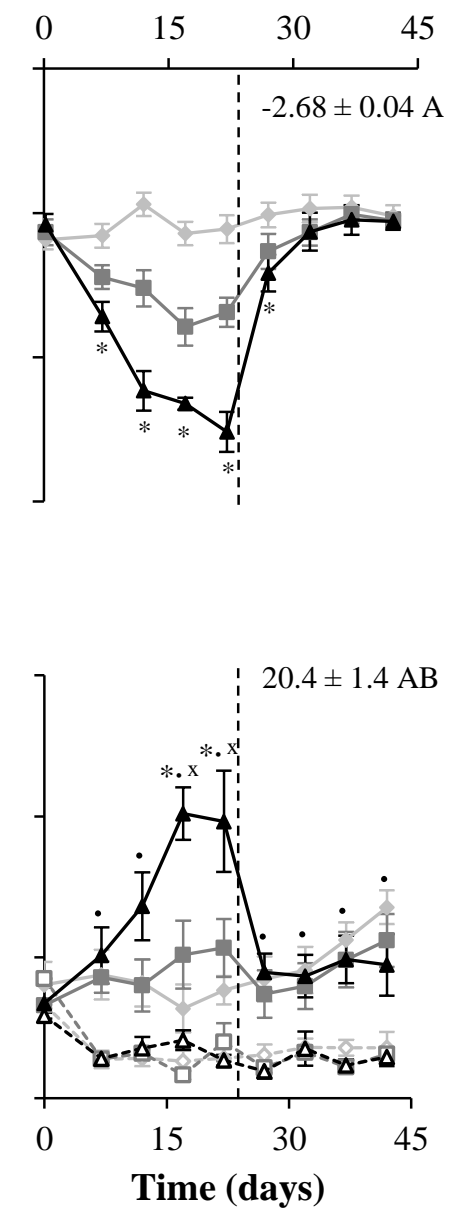

Time (days) 
6060 AND

(a)

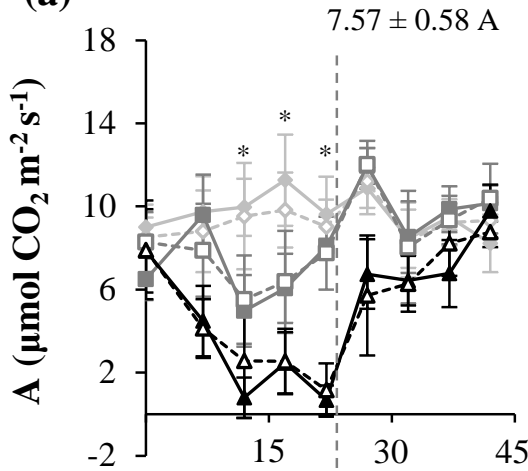

(b)

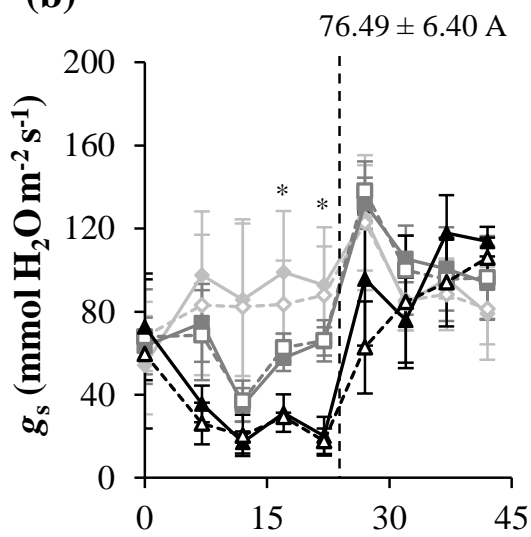

(c)

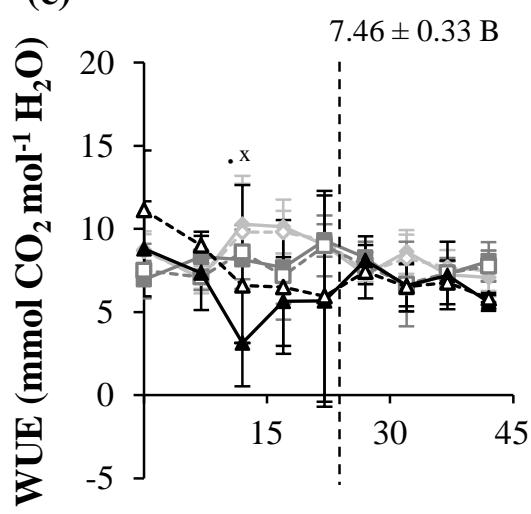

(d)

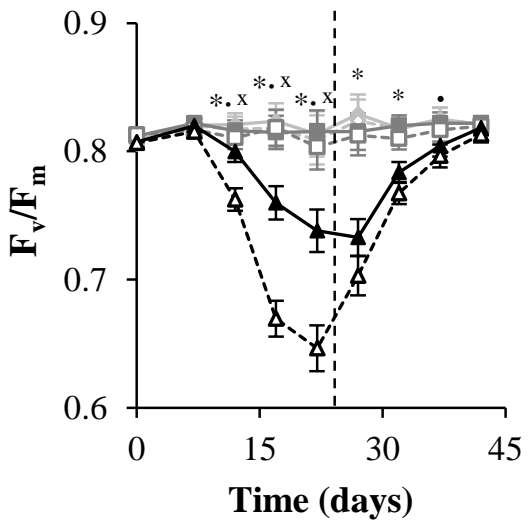

POL

$8.04 \pm 0.61 \mathrm{~A}$

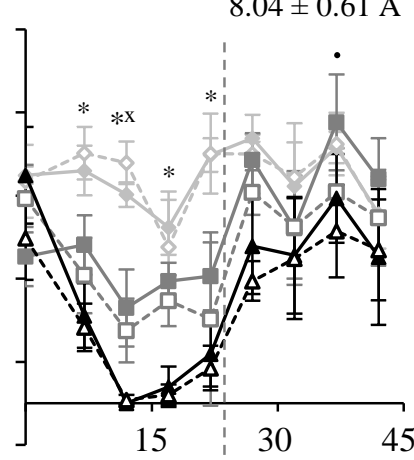

$81.27 \pm 6.78 \mathrm{~A}$

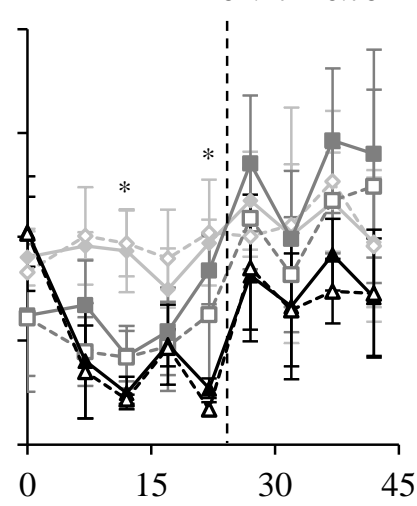

$7.55 \pm 0.34 \mathrm{~B}$

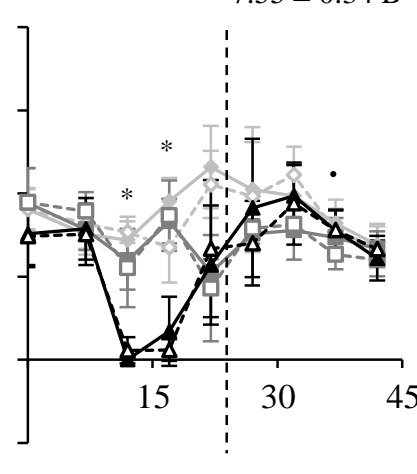

$0.819 \pm 0.003 \mathrm{~A}$

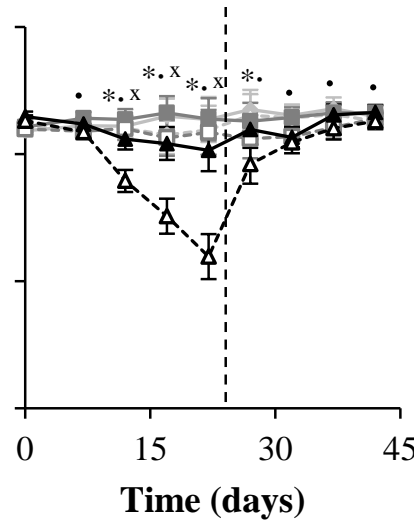

JER

$6.80 \pm 0.56 \mathrm{~A}$
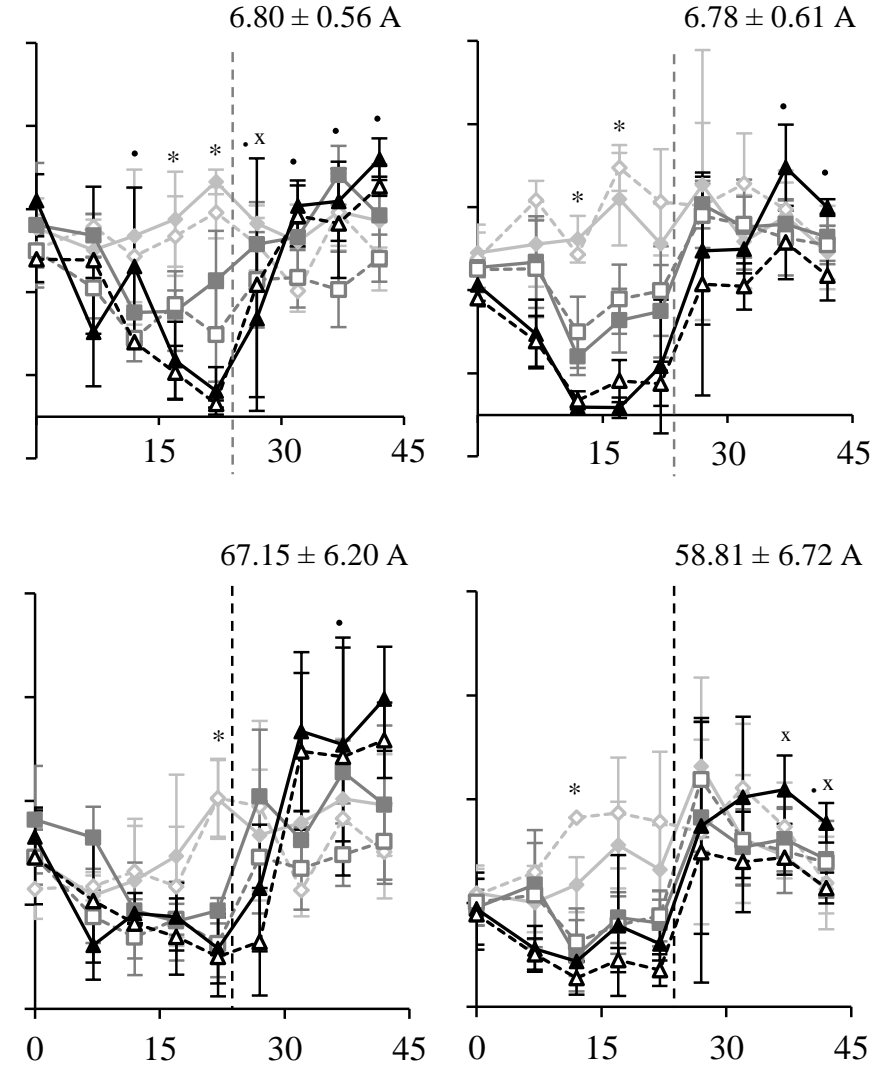

$8.84 \pm 0.34 \mathrm{~A}$

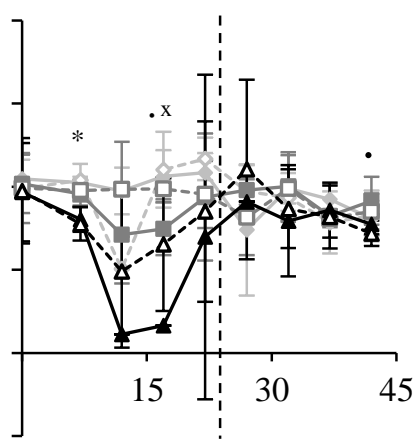

$0.820 \pm 0.003 \mathrm{~A}$
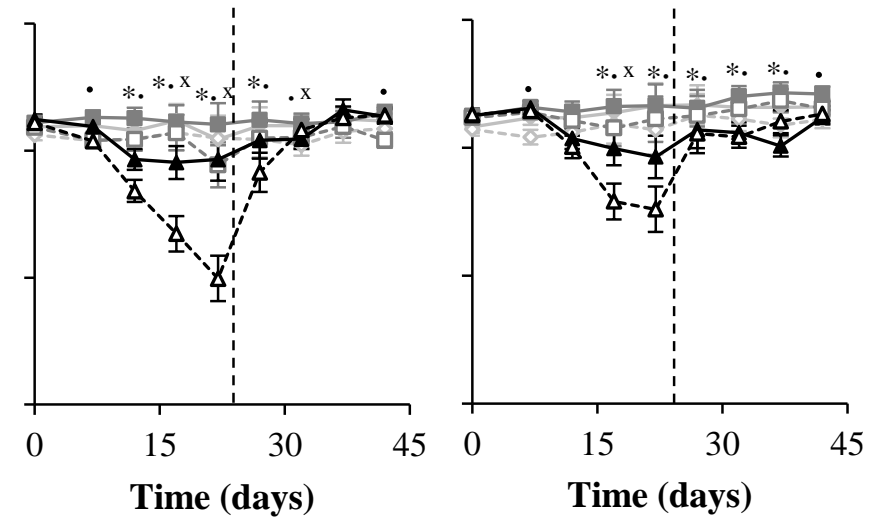
(a)

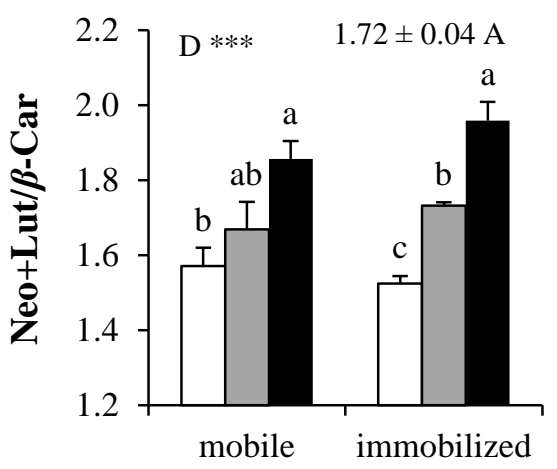

(b)

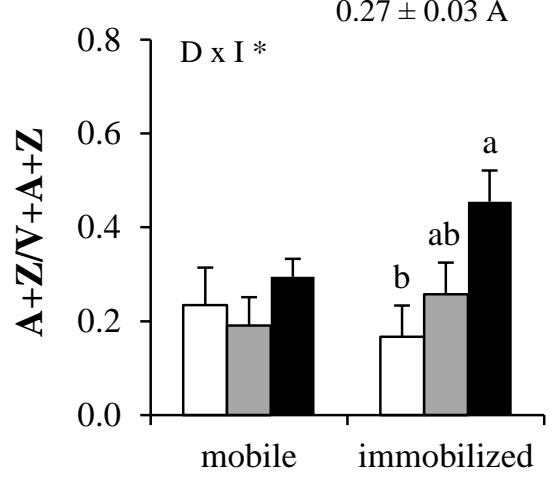

(c)

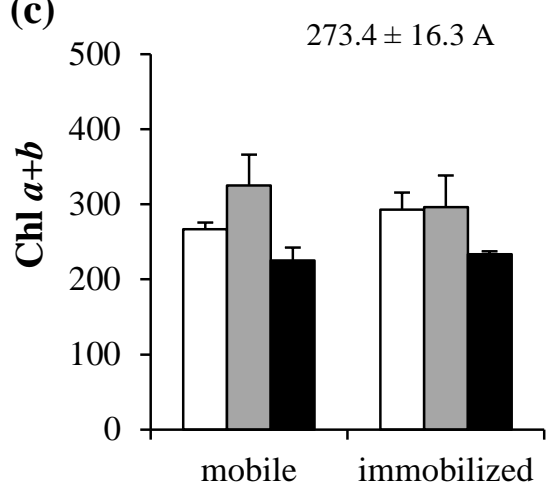

(d)

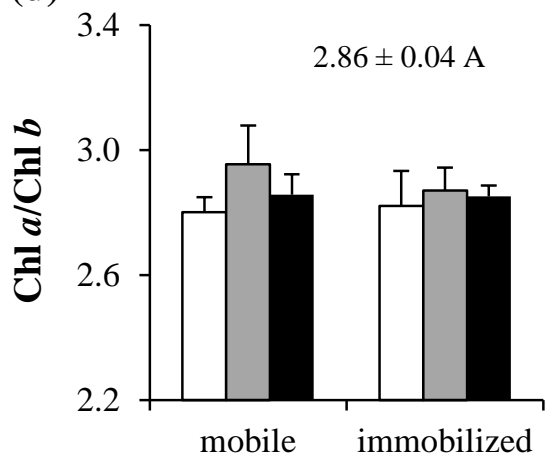

POL

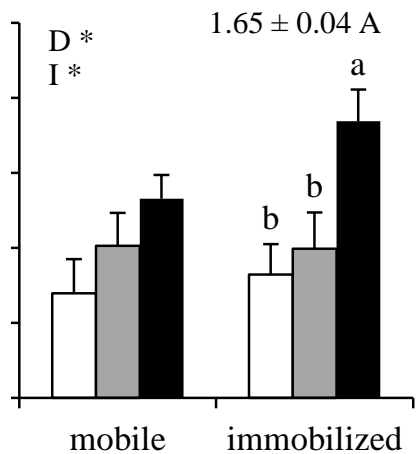

$0.35 \pm 0.03 \mathrm{~A}$
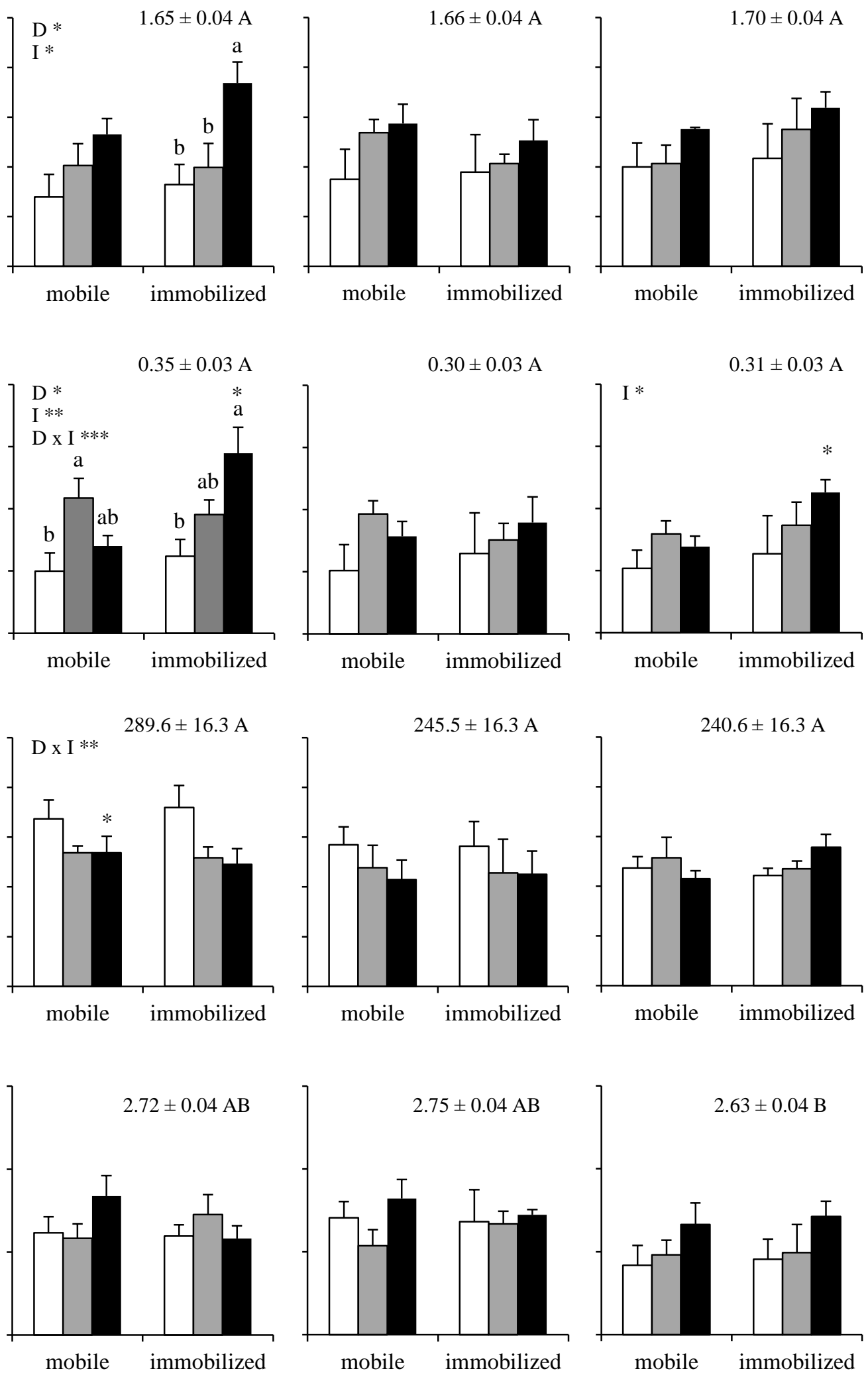


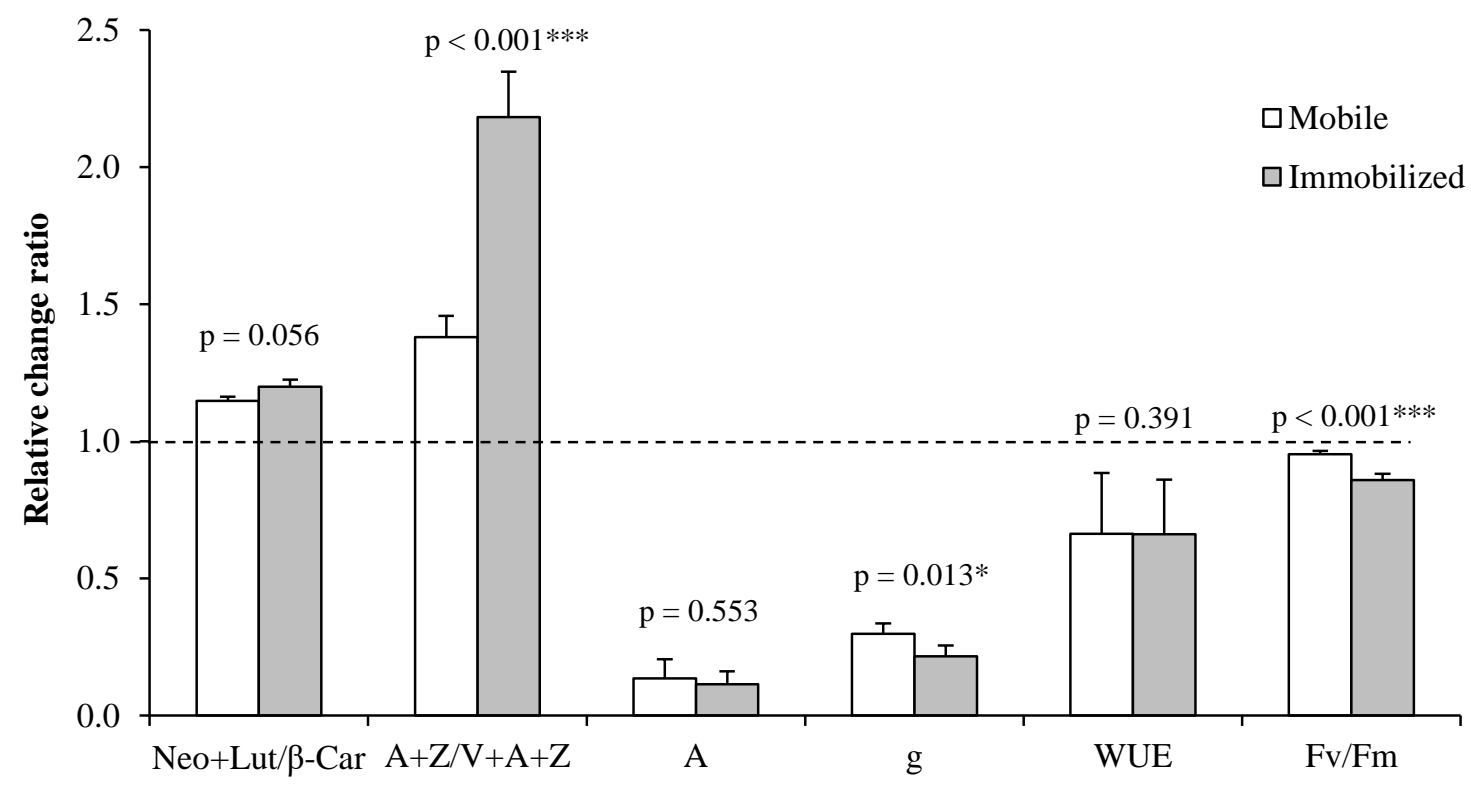




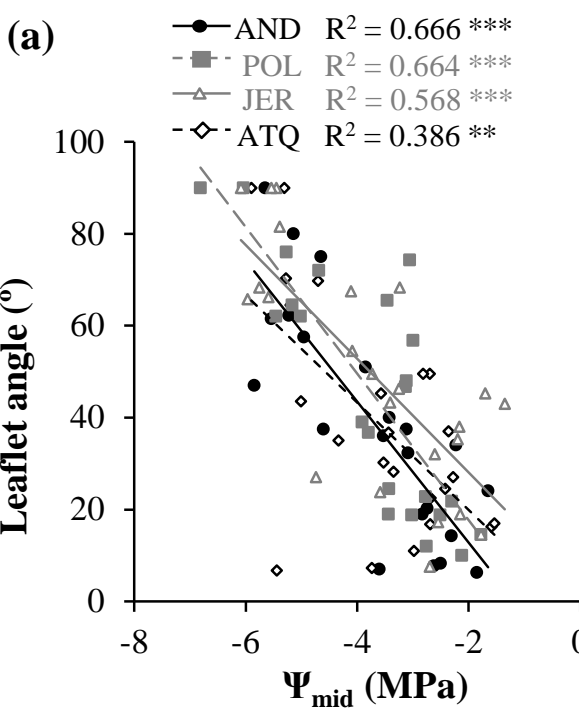

(d)

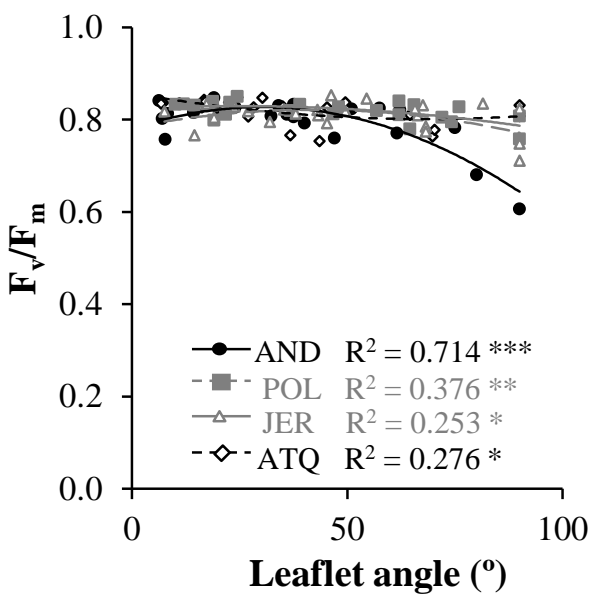

(b) $\quad \longrightarrow$ AND $\mathrm{R}^{2}=0.766 * *$ - $-\mathrm{POL} \mathrm{R}^{2}=0.742 * *$ $\triangle-\mathrm{JER}$

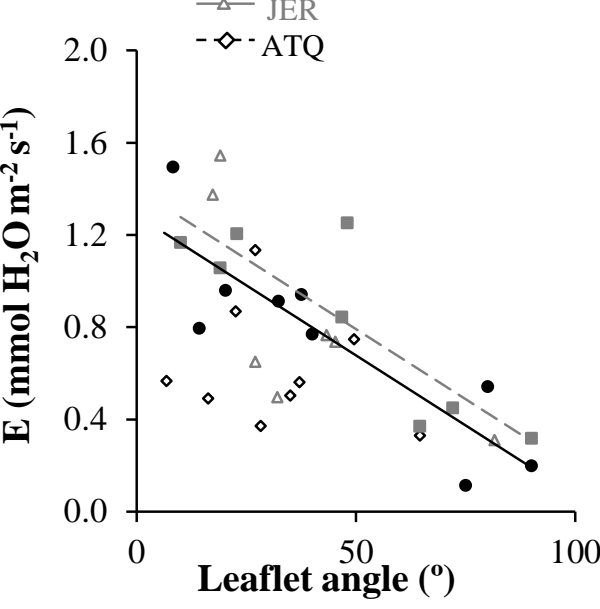

Leaflet angle $\left({ }^{\circ}\right)$
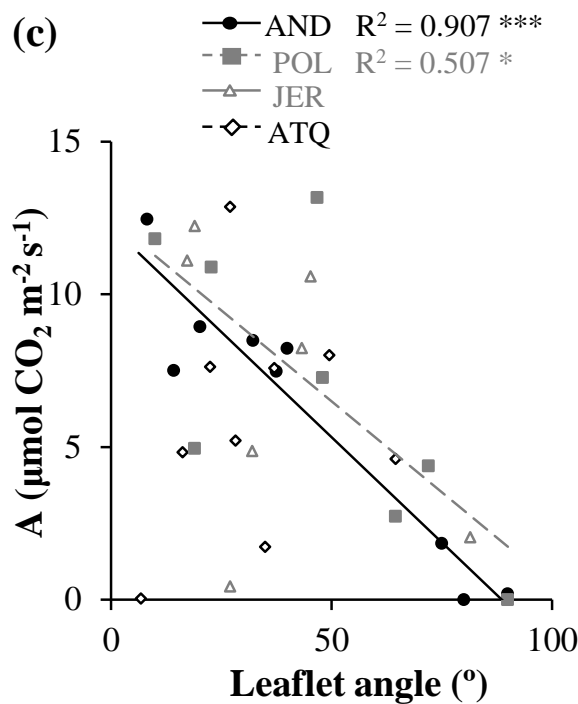

(e)

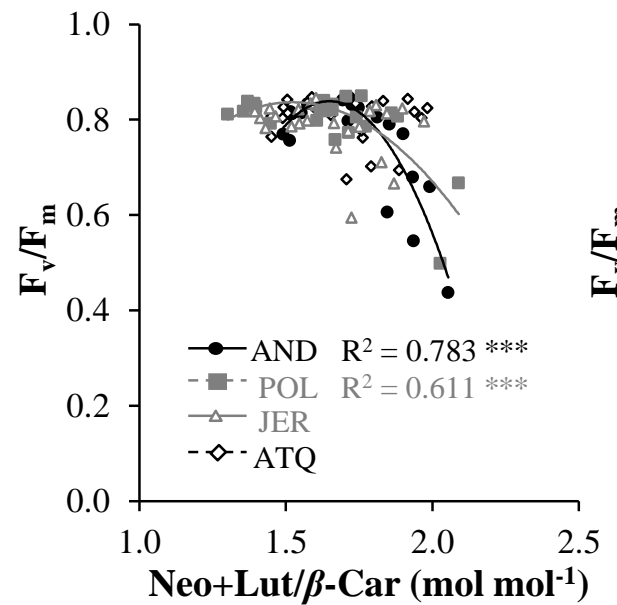

(f)

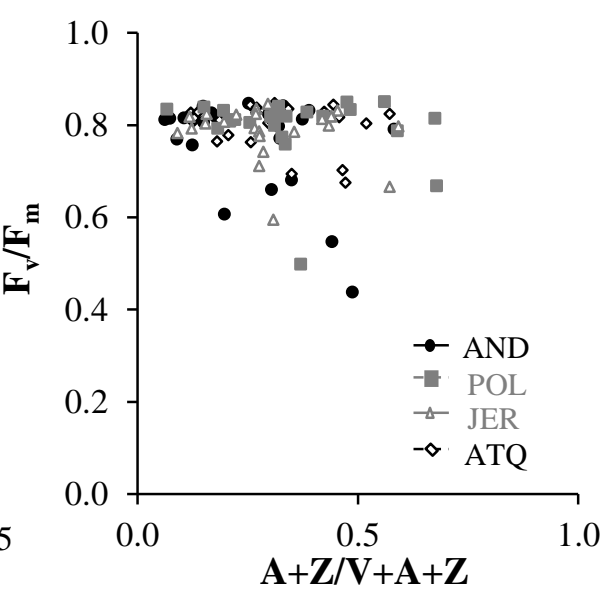


(a)

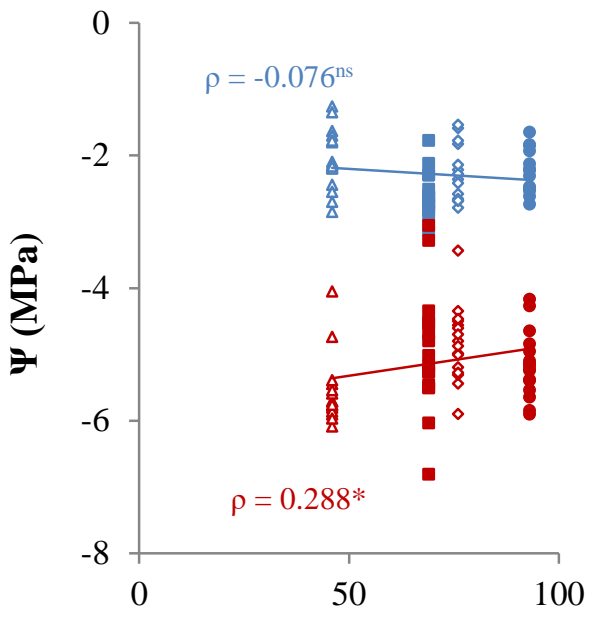

Precipitation seasonality (\%) (b)

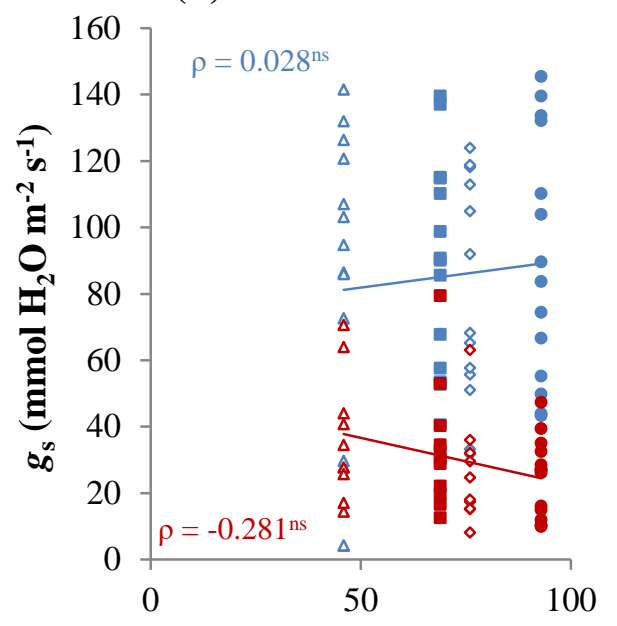

Precipitation seasonality (\%) (c)

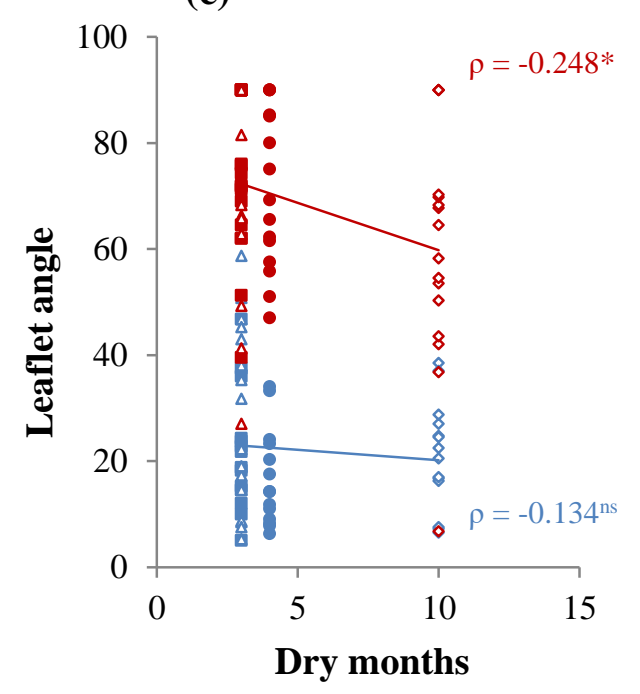

(f)

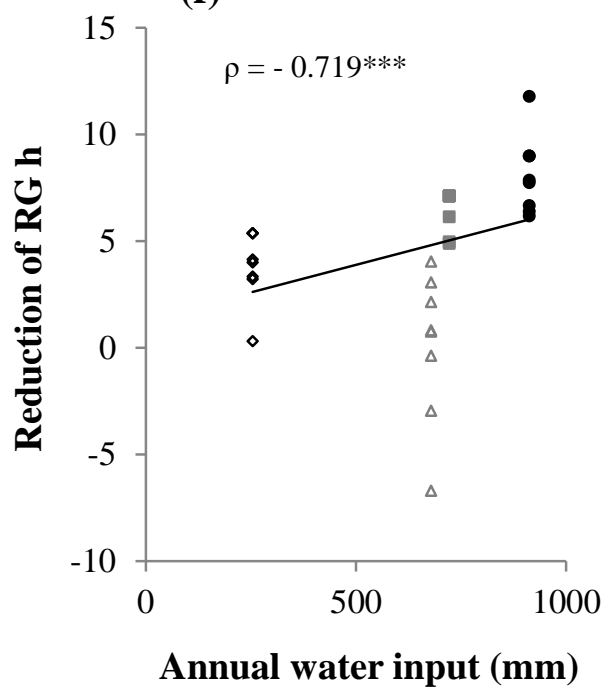

Annual water input (mm)

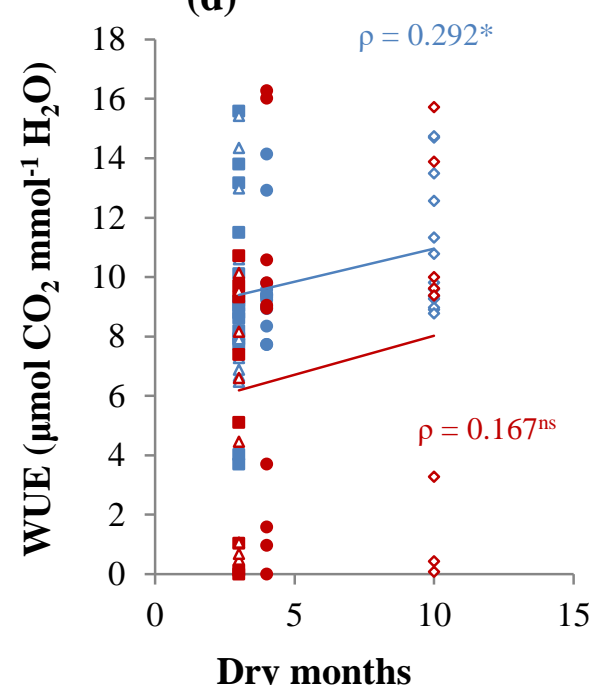

Dry months (e)

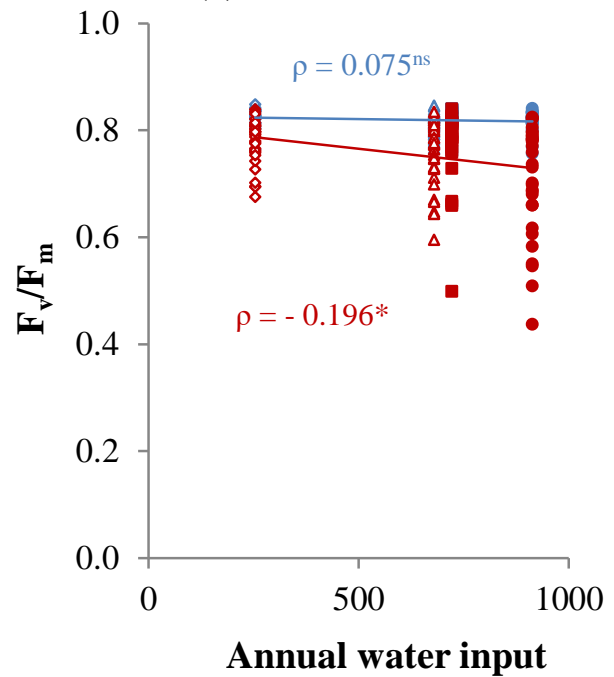

